\title{
ACCURATE COVER CRACK MODELLING OF REINFORCED CONCRETE STRUCTURES SUBJECTED TO NON-UNIFORM CORROSION
}

Xun $\mathrm{Xi}^{1,2}$, Shangtong Yang ${ }^{1 *}$ and Chun-Qing $\mathrm{Li}^{3}$

1 Department of Civil and Environmental Engineering, University of Strathclyde, Glasgow, G1 1XJ, United Kingdom.

2 School of Civil and Resource Engineering, University of Science and Technology Beijing, Beijing, 100083, China.

3 School of Engineering, RMIT University, Melbourne, Vic 3001, Australia.

*Corresponding author. Tel: +44 141548 3273. Email: shangtong.yang@strath.ac.uk. 


\title{
ACCURATE COVER CRACK MODELLING OF REINFORCED CONCRETE STRUCTURES SUBJECTED TO NON-UNIFORM CORROSION
}

\begin{abstract}
Concrete cover cracking caused by reinforcement corrosion is a significant durability problem of reinforced concrete structures. Extensive research has been carried out in the last few decades while most were focused on corrosion of a single reinforcing bar. Very little research has examined the whole cover cracking of reinforced concrete structures due to multiple reinforcement corrosion. This paper develops a numerical model to predict the structural failure of the whole cover of concrete induced by corrosion of multiple reinforcing bars. Moreover, a non-uniform corrosion model is established based on experimental results, in contrast to conventional uniform assumption. Two typical cover failure modes under the non-uniform corrosion of multiple reinforcing bars are identified and discussed. The effects of cover thickness, reinforcement spacing, fracture energy of concrete, etc., on cover cracking patterns and crack width are also investigated. The derived numerical model is verified by comparing the results with those from experiments in literature. Accurate prediction of concrete cover cracking can allow timely maintenance of existing structures and rational design for new buildings which prolongs the service life of the reinforced concrete structures.
\end{abstract}

Keywords: Durability, Corrosion, Reinforcement, Concrete Structures, Simulation models, Finite element method.

\section{INTRODUCTION}

Reinforced concrete (RC) is the most common type of structures used in building, bridges, retaining walls, tunnels and the indeed any physical infrastructure built on and under the ground. RC structures can suffer from corrosion of reinforced steel caused by chloride $\left(\mathrm{Cl}^{-}\right)$ and/or carbon dioxide $\left(\mathrm{CO}_{2}\right)$ diffusion into concrete. Failure of RC structures induced by corrosion of reinforcement is the greatest threat to the durability and service life of civil 
engineering construction. It is estimated that the annual direct cost of corrosion for highway bridges in the USA is $\$ 8.3$ billion (Koch, Brongers, Thompson, Virmani and Payer, 2002).

Considerable research has been carried out in predicting corrosion-induced surface cracking and linking the surface crack width with steel loss ratio. Amongst the existing studies, most focus on uniform corrosion of a single reinforcing bar (Andrade, Molina and Alonso 1993, Liu and Weyers 1998, Pantazopoulou and Papoulia 2001, Li 2003, Li 2005, Bhargava, Ghosh, Mori and Ramanujam 2006, Guzmán, Gálvez, and Sancho 2011, Li and Yang 2011). However, due to the actual diffusion nature of chloride ingress, the corrosion process is seldom uniform along the reinforcing bar; the chloride ions as well as oxygen and moisture normally penetrate onto the surface of the reinforcement at different rates from different sides of concrete. This has been experimentally confirmed by Yuan and Ji (2009) who conducted accelerated corrosion tests on reinforced concrete samples in an artificial climate chamber and found that, only a half of the reinforcing bar, facing concrete cover, was corroded and the corrosion expansion was in a semi-elliptical shape. Moreover, Jang and Oh (2010) introduced a factor $\alpha$ defined as the ratio of the depth of non-uniform corrosion to that of uniform corrosion to account for the nonuniform degree of corrosion; they have found that the pressure to cause cover cracking under non-uniform corrosion conditions ( $\alpha=4$ to 8 ) is much lower than that of uniform corrosion case. Muthulingam (2016) described the dynamics of spatio-temporal evolutions of corrosion initiation in rebars and stirrups through a Gaussian function. Chen and Leung (2015) developed a non-uniform corrosion model based on varying chloride penetration and Fick's second law and postulated that, for the given corrosion degree, the surface crack width for non-uniform corrosion is considerably larger than that for uniform corrosion. Du, Jin and Zhang (2014) simulated the different failure patterns of side-located and corner-located reinforcing bars separately under non-uniform corrosion by assuming the surrounding concrete as a three-phase heterogeneous material. Zhao et al. (2011) proposed a Gaussian distribution for the non- 
uniform corrosion caused displacement and simulated the cracking of concrete by considering corner rebar corrosion.

However, most previous work on non-uniform corrosion induced cracking of concrete cover has been focused on a single reinforcing bar (Balafas and Burgoyne 2010, Al-Harthy, Stewart and Mullard 2011, Tran, Nakamura, Kawamura and Kunieda 2011, Sanz, Planas and Sancho 2013, Šavija, Luković, Pacheco and Schlangen 2013, Du et al. 2014, Chen and Leung 2015, S.T. Yang, K.F. Li and C.Q. Li 2015). In fact, the interaction between the concentrated stress fields of different reinforcement in a RC structure cannot be neglected. As a result, different cracking patterns for the whole cover of structure may exist. Experimental results on accelerated corrosion tests (electric current method) of multi reinforcing bars have suggested that the cracks from each bar tend to interact and inter-connect with each other, depending on spacing between the bars (Liu and Weyers 1998, Vu, Stewart and Mullard 2005, Val, Chernin, and Stewart 2009, Al-Harthy et al. 2011, Mullard and Stewart 2011). Leon and Val (2009\& 2011) simulated the crack pattern of concrete cover by considering simultaneous uniform corrosion of two reinforcing bars. Zhang, Ling and Guan (2017) modelled the cover cracking of a RC structure with two reinforcing bars under non-uniform corrosion. In their model, the two reinforcing bars are assumed middle bars and the cracking is equivalently simulated via damage plasticity model. To the knowledge of the authors, there is very limited research addressing the structural failure of the concrete cover by considering non-uniform corrosion of multi reinforcing bars and none of the existing studies could simulate discrete crack propagation or satisfactorily explain the interactive cracking mechanisms of the cover failure of RC structures.

This study attempts to develop a numerical method to simulate the cover failure of RC structures caused by non-uniform corrosion of multiple reinforcing bars. A non-uniform corrosion model is first formulated based on experiment results. Under the expansive 
corrosion-induced force, the arbitrary discrete cracks of concrete are modelled through the insertion of a considerable number of cohesive crack elements in a sufficiently fine mesh of the structure. The cracking patterns of the concrete cover are examined and the steel loss ratios to cover cracking are investigated. Further, crack widths for all cracks are determined, after the comparison with experimental results in literature. Moreover, a parametric study is carried out to investigate the effects of some key parameters, e.g., cover thickness, structural confinement effect and corrosion model on the cover cracking pattern, cracking steel loss ratio, and crack width.

\section{NON-UNIORM CORROSION MODEL}

When the reinforcement in concrete is corroded, the corrosion products will accumulate and push the surrounding concrete outwards which cause cracking and delamination of RC structures. As shown in Figure $1, \phi$ is the diameter of the reinforcing rebar and $d_{0}$ is the thickness of the annular layer of concrete pores at the interface between the bar and concrete, often referred to the "porous zone"(Liu and Weyers 1998) or "corrosion accommodation zone"(Caré, Nguyen, L'Hostis and Berthaud 2008). Usually $d_{0}$ is constant once concrete has hardened. In this study, $d_{0}$ is assumed $12.5 \mu \mathrm{m}$ (Yang et al. 2015). Depending on the level of corrosion, the products of corrosion may occupy up to several times more volume than the original steel (Šavija et al. 2013). It is assumed that no stress is produced and exerted on the concrete until the "porous zone" between reinforcement and concrete is fully filled by the corrosion products. As the corrosion products proceed further in concrete, a band of corrosion products forms, as shown in Figure 1(a).

Due to the fact that the chlorides, as well as moisture and oxygen, reach the reinforcement surface at different rates through top side of the concrete structure, it is very rare to have uniform corrosion around the reinforcement. This is particularly the case for offshore RC 
structures as the surface facing the splashes has much faster ingression rate and hence more severe corrosion occurs on this side. It has been found that the front of corrosion products for the half of rebar facing concrete cover is in a semi-elliptical shape, while corrosion of the opposite half of rebar is negligibly small and can be neglected (Yuan and Ji 2009).

As illustrated in Figure 1(b), there may be three bands accommodating the corrosion products: the semi-elliptical band of corroded steel with maximum thickness $d_{c o-s t}$, the porous circular band $d_{0}$ and the semi-elliptical rust band with maximum thickness $d_{m}$ (also referred to as corrosion expansion displacement in this paper). The front of the corrosion is in a semielliptical shape with the semi-major axis equal to $\phi / 2+d_{0}+d_{m}$ and the semi-minor axis equal to $\phi / 2+d_{0}$.

To determine the displacement boundary condition of the concrete cylinder, the function of the semi-ellipse of the corrosion front needs to be derived. It is known that, in rectangular coordinate system, the function for an ellipse can be expressed as follows:

$$
\frac{y^{2}}{\left(\frac{\phi}{2}+d_{0}+d_{m}\right)^{2}}+\frac{x^{2}}{\left(\frac{\phi}{2}+d_{0}\right)^{2}}=1
$$

Equation (1) can be transformed in a polar coordinate system. By considering the original location of inner boundary of the concrete, i.e., $\phi / 2+d_{0}$, the displacement boundary condition of the concrete structure can be derived as follows,

$$
r=\frac{\left(\phi+2 d_{0}+2 d_{m}\right)\left(\phi+2 d_{0}\right)}{\sqrt{\left(2 \phi+4 d_{0}\right)^{2}+16 d_{m}\left(\phi+2 d_{0}+d_{m}\right) \cos ^{2} \theta}}-\frac{\phi}{2}-d_{0}
$$

where $0 \leq \theta \leq \pi$. Equation (2) will be used as the inner boundary condition of the concrete in formulating the finite element model. 
According to the model derived in (Yang, K.F. Li and C.Q. Li 2017), the corrosion expansion displacement $d_{m}$ also can be expressed as follows:

$$
d_{m}=\frac{4 W_{\text {rust }}}{\pi \phi}\left(\frac{1}{\rho_{\text {rust }}}-\frac{\alpha_{\text {rust }}}{\rho_{\text {st }}}\right)-2 d_{0}
$$

where $W_{\text {rust }}$ is the amount of corrosion products in unit length, $\rho_{\text {rust }}$ is the density of corrosion products and $\rho_{s t}$ is the density of steel bar.

The amount of rust replacing the corroded steel $W_{s}$ can be expressed as (Yang et al. 2017):

$$
W_{s}=\alpha_{\text {rust }} W_{\text {rust }} \frac{\rho_{\text {rust }}}{\rho_{\text {st }}}
$$

Therefore, the steel loss ratio $\eta$ can be derived as follows:

$$
\eta=\frac{W_{s}}{\rho_{\text {rust }}} \frac{4}{\pi \phi^{2}}
$$

Substituting Equation (4) and Equation (5) into Equation (3), it can be derived that:

$$
d_{m}=\frac{\eta \rho_{s t} \phi}{\alpha_{\text {rust }}}\left(\frac{1}{\rho_{\text {rust }}}-\frac{\alpha_{\text {rust }}}{\rho_{\text {st }}}\right)-2 d_{0}
$$

\section{DISCRETE CRACK MODEL}

Under the expansive force of the corrosion products, the $\mathrm{RC}$ structure is predominantly controlled by tension failure, i.e., cracking. Therefore, the compressive property of the concrete can be assumed to be elastic without defining the compression failure. The cracking of concrete can be modelled by the cohesive crack model; in this model, a fictitious crack is formed to represent the fracture process zone (Hillerborg, Modeer and Petersson 1976). The constitutive stress-displacement relation $(\sigma-\delta)$, can be shown in Figure 2. The tensile stress linearly increases until its maximum value, i.e., tensile strength $f_{t}^{\prime}$; such a linearity is determined by a penalty stiffness $K_{p}$. After reaching the peak value, the tensile stress decreases, following 
certain strain softening rules, e.g., linear, bi-linear, exponential, etc. The area underneath the curve in Figure 2 is known as the fracture energy $G_{f}$. The concept of penalty stiffness evolves from the elastic stiffness which is obtained by dividing the elastic modulus of the concrete by its thickness. Since cohesive interface is normally very thin or even of zero thickness, the elastic stiffness of the cohesive interface approaches infinitesimally large. This makes sense as the interface should be stiff enough prior to the initiation of crack to hold the two surfaces of the bulk concrete together, leading to the same performance as that of no interface existing. However, the elastic stiffness cannot be too large as it will cause convergence problems due to ill-conditioning of the numerical solver. The value of penalty stiffness is set as $1000 \mathrm{GPa}$ which is enough large to provide the same response of intact concrete before cracking (Yang, $\mathrm{Su}$, Chen and Liu. 2009).

To model the arbitrary cracking in concrete, the cohesive elements are embedded everywhere in the mesh of concrete; very fine mesh is produced to ensure the random crack paths. The insertion process of cohesive elements is shown in Figure 3. Figure 3(a) illustrates the initial mesh generated, which consists of triangle elements only. All the initial nodes are replaced by certain number of new nodes at the same location. The number of newly created nodes depends on the number of the elements connecting to the original node. As shown in Figure 3, a node is initially connected to 6 triangle elements; therefore, this node is replaced by 6 newly created nodes. Subsequently, 4 nodes at the interface between two triangle elements are identified and linked to form a cohesive element. The thickness direction of cohesive element is defined as the normal direction to the two edges of cohesive element which shares the same edges of the adjacent triangle elements. In this way, all the interfaces between the triangle elements are inserted of cohesive elements. The cohesive elements are shown in red in Figure 3. This insertion process was conducted by a script written in Python. Moreover, it should be mentioned that the cohesive elements generated are of zero thickness in geometry. 
The two nodes of a cohesive element, in the thickness direction, share the same coordinates before loading. The constitutive/calculation thickness of the cohesive elements is 1.0 for the convenience of transformation between strain and displacement.

\section{FORMULATION OF FINITE ELEMENT MODEL}

Concrete structures, such as concrete beams, are often reinforced by a number of steel bars. In this study, a RC beam with multiple numbers (typically four) of tensile reinforcing bars is modelled. The mechanisms for cases where two or three tensile bars are used are covered in the case of four bars. The configuration of the concrete structure with four reinforcing bars (the spacing between steel bars is the same) is shown in Figure 4. The structure is modelled in 2D since it is a plane strain problem. In light of reducing the computing time, only half of the structure is modelled due to the symmetry of the structure and the loading.

Two elements are employed in this study, i.e., 4-node cohesive elements at all interfaces between the triangle elements, and 3-node plane strain element for the bulk intact concrete. Reduced integration is used for the plane strain element. As a result, the damage evolution of the cohesive element is combined with the elastic deformation of the bulk concrete in the overall response. The elements around the reinforcing bars are generated by sweep method and other elements are generated by free mesh method. The mesh of the region close to the corrosion products is finer than the mesh in other region. In overall, very fine mesh is initially generated before inserting sufficient number of cohesive elements. The meshed structure is shown in Figure 5. There are 16,610 solid triangle elements and 24,700 cohesive elements inserted, for half of the structure. The potential crack area of this model has finer mesh than other regions. The expansive behaviour of non-uniform corrosion is modelled by applying radial expansive displacement to the concrete structure. As discussed, the displacement is applied at the top half boundary of the structure which is facing the cover surface. 
For the strong and weak forms, discretization and linearization of continuum elements and discontinuity surfaces, see the reference (Mergheim, Kuhl and Steinmann 2005). Damage initiation refers to the beginning of degradation of the response of a material point. It has been indicated that Mode I fracture dominate crack propagation induced by corrosion of reinforcement and shear fracture properties has little effect on mixed-mode fracture of concrete for homogeneous numerical model (Gálvez, Cendón and Planas 2002, Farid Uddin, Numata, Shimasaki, Shigeishi and Ohtsu 2004). Therefore, only Mode I fracture (i.e., cracking) is considered in this paper. The process of degradation begins when the tensile stress reaches the tensile strength of the concrete for the Mode I fracture, expressed as follows,

$$
\frac{\left\langle\sigma_{1}\right\rangle}{f_{t}^{\prime}}=1
$$

where $\left\langle\sigma_{1}\right\rangle=\left\{\begin{array}{ccc}\sigma_{1} & \text { for } & \sigma_{1}>0 \\ 0 & \text { for } & \sigma_{1}<0\end{array}\right.$. The operation $\left\langle\sigma_{1}\right\rangle$ is to ensure that compressive stress state does not initiate damage. To prevent mesh sensitivity in FE analysis, the stressdisplacement relation is used rather than stress-strain relation. As the distance between the nodes is used as a crack measure rather than a change in strain (which depends on the element length), the mesh dependency is significantly reduced.

Once the damage is initiated, the normal stress of this element softens in a manner as defined. The evolution of damage is governed by the softening curve. A scalar damage variable, D, represents the overall damage in the material and captures the combined effects of all the active mechanisms. It initially has a value of 0 , followed by monotonically evolvement from 0 to 1 upon further loading. The damage parameter $D$ is introduced to the stress calculation as follows:

$$
\sigma=(1-D) \sigma_{u}
$$

where $\sigma_{u}$ is the undamaged stress predicted by the elastic traction-separation behaviour for the current strains, as shown in Figure 6. 
Severe convergence difficulties is a common problem in the execution of FE programmes for materials exhibiting softening behaviour and stiffness degradation under implicit scheme as in most FE programmes. Sudden dissipation of energy will make the computation more dynamical. An artificial viscosity is therefore used to overcome the convergence difficulties by making the stiffness matrix of the material positive for sufficiently small time increments. This viscosity regularizes the constitutive relation of the cohesive element by modifying the stiffness reduction variable $D$ as follows,

$$
\dot{D_{v}}=\frac{D-D_{v}}{\mu}
$$

where $\mu$ is the viscosity parameter which can be specified in the property of cohesive element and $D_{v}$ is the viscous stiffness degradation variable. Once $\mu$ and $D$ are known, $D_{v}$ can be determined. In this paper, the artificial viscosity value is set as 1e-5 which helps improve the rate of convergence without compromising results (Yang S.T., Li, K. F. and Li C.Q., 2017). The constitutive response of damaged element with viscosity parameter is given as,

$$
\sigma=\left(1-D_{v}\right) \sigma_{u}
$$

\section{NUMERICAL EXAMPLE AND VERIFICATION}

To demonstrate the application of the derived FE model in simulating the cover cracking of $\mathrm{RC}$ structures with corrosion of multi reinforcing bars, two examples for two typical cracking mechanisms are first presented. The values for all the basic parameters are shown in Tables 1 and 2, together with their sources. The typical cracking mechanisms obtained are shown in Figure 7. Mirror function is used to show the mechanical behaviour of the whole structural cover, since only half of the structure is modelled due to symmetry. Figure 7(a) illustrates the first cracking mechanism with $40 \mathrm{~mm}$ for cover thickness. For the first mechanism, there are two types of cracks, i.e., one side crack and one through crack between reinforcing bars, as 
shown in Figure 7(a). Such a mechanism is a typical delamination failure of the structural cover. The other mechanism, as shown in Figure 7(b), however, has the side crack, the through crack and one more crack occurring, propagating from the top surface to the corner bar. This cracking pattern happens with $20 \mathrm{~mm}$ for cover thickness. The side crack and the top crack can cause spalling failure of the corner cover. It is also interesting to find out that cracking behaviour for the corner and middle bars are significantly different, although the corrosion models used might be the same.

Figure 8 illustrates the maximum principal stress for the RC structure with cover thickness $40 \mathrm{~mm}$, under different corrosion expansion displacements $d_{m}$ of $5.51 \mu \mathrm{m}, 55.00 \mu \mathrm{m}, 64.32$ $\mu \mathrm{m}$ and $151.64 \mu \mathrm{m}$, respectively. At minor corrosion level, e.g., $d_{m}=5.51 \mu \mathrm{m}$, the stress starts to concentrate around the two sides of the inner boundary - roughly at 10 degrees above the horizontal direction. As the corrosion develops, damage/cracking is initiated and the stress concentration moves outwards. It should be note the top surface of concrete is in tension while the inner concrete at top of rebar is in compression, which has a good agreement with analytical model derived by Yang (S. T. Yang, K. F. Li and C. Q. Li 2017). The through crack first appears shortly after the two stress concentrations from neighbouring reinforcing bars (can also be referred to as the cohesive crack tip) join with each other, i.e., from (2) to (3) in Figure 8. After the through crack is completely formed, the side crack gradually approaches the side surface of the concrete structure. For this cracking mechanism (1), other than the internal through crack, there is only one external visible crack on the side of the concrete structure.

Figure 9 shows the maximum principal stress for the cracking mechanism 2 identified under the corrosion expansion displacements of $5.54 \mu \mathrm{m}, 27.64 \mu \mathrm{m}, 60.60 \mu \mathrm{m}$ and $160.67 \mu \mathrm{m}$, respectively. The behaviour of the structure is quite similar to the cracking mechanism 1, up to the formation of the through crack. After that, the top crack appears firstly because tensile stress concentrates at top surface of concrete. It is very interesting to see that the corrosion-induced 
cracking is not always initiated from inside to outside of the structure - the top crack starts from the outer surface and propagates inwards to the reinforcing bar. This is because, under the non-uniform expansion, the top surface of the structure is in tension while the region around the top of the reinforcing bar is in bi-axial compression, as shown in Figure 9 (2). Therefore, the crack will sensibly start from the tension region at the surface. Such a phenomenon has been evident in some experiments, e.g., S. Caré et al. (2009). Once the side crack propagates to the side surface, spalling at the corner of the structure happens.

According to Equation (6) and values in Tables 1 and 2, Figure 10 is plotted which shows the steel loss ratio as a function of corrosion expansion displacement $d_{m}$. It can be found that, when steel loss ratio increases to about $0.07 \%$, the corrosion products fully fill into the "porous zone"; from this point, the corrosion expansion displacement $d_{m}$ starts to increase linearly with the steel loss ratio. It has been demonstrated both in Figure 10 and Equation (6) that $d_{m}$ increases linearly with the steel loss ratio, after an initial period of rust filling in the porous zone.

To verify the developed numerical method, the results are compared to those from (H. L. Ye, N. G. Jin, C. Q. Fu and X. Y. Jin, 2017). It has been searched very hard from the literature for the experimental results on cracking of RC structures with multiple reinforcing bars under nonuniform corrosion which have been proven extremely limited. Ye et al. (2017) has reported the relationship between the steel loss ratio and the surface crack width and, importantly, the corrosion products distribution of their C20 samples is very similar to that proposed in this paper which validates the ground for comparison. Same inputs from the test specimen are used in the numerical simulation, as presented in Table 3. The numerical model has the same geometric parameters with that form experiments (Ye et al. 2017). The comparisons of crack width from the developed numerical model and the experiments (Ye et al. 2017) are illustrated in Figure 11. The crack width for numerical model is slightly larger than that for experiments. 
It is perhaps caused by the assumption of $2 \mathrm{D}$ plain problem because the constraint effect in the third dimension is ignored. It can be postulated that the simulated results are in reasonably good agreement with the experimental values.

\section{PARAMETRIC STUDY}

Fracture energy of concrete is usually considered as a key parameter controlling cracking of concrete structures. The spacing between the steel reinforcing bars is another important parameter controlling the failure of corrosion-affected RC structures. In this study, three fracture energy values $(60 \mathrm{~N} / \mathrm{m}, 90 \mathrm{~N} / \mathrm{m}$ and $120 \mathrm{~N} / \mathrm{m})$ and three clear spacing values $(30 \mathrm{~mm}$, $45 \mathrm{~mm}, 60 \mathrm{~mm}$ ) for cover thickness $20 \mathrm{~mm}$ are selected to simulate cracking of concrete cover induced by non-uniform corrosion. The crack patterns under different combinations of reinforcement clear spacing and fracture energy of concrete are shown as Figure 12. It can be found that, for relatively low fracture energy values of concrete and short reinforcement spacing, the non-uniform corrosion of rebar tend to cause delamination of concrete cover. While combined delamination and corner spalling of concrete cover will occur for large values of fracture energy and reinforcement spacing.

To better understand the mechanisms of different crack patterns, the displacements of external element of the top crack and the internal element of side crack are shown as a function of $d_{m}$ in Figure 13. These two elements were chosen because they represent the location of crack initiation for the two cracks respectively. It can be seen that when the fracture energy of concrete is $60 \mathrm{~N} / \mathrm{m}$, the displacement of the first cohesive element of the side crack is much larger than that of the potential top crack (no actual top crack for this case). Once the side crack propagates to the side surface, there is a sudden increase of the displacement of the side crack because of the energy release. In the meantime, the displacement of the potential top crack suddenly decreases to zero, which indicates unloading behaviour of the structure. This is also 
why there is no top crack occurring in this case. However, when the fracture energy is $120 \mathrm{~N} / \mathrm{m}$, the displacement of the first cohesive element of the side crack gradually increases, together with the increase of that of the top crack. In this case, these two cracks develop more evenly as the corrosion products accumulate.

The thickness of concrete cover is an important structural parameter affecting cracking behaviour of concrete. As shown in Figure 7, with the same mechanical parameters and reinforcement spacing, the non-uniform corrosion of rebar could lead to delamination of RC structure for a thicker cover (i.e., $40 \mathrm{~mm}$ ). However, combined delamination and corner spalling will happen for a thin cover (i.e., $20 \mathrm{~mm}$ ). Figure 14 shows the crack patterns of concrete induced by non-uniform corrosion under combinations of cover thickness and reinforcement spacing. The fracture energy of concrete is $120 \mathrm{~N} / \mathrm{m}$. It can be found that, the delamination of concrete cover has been found taking place for thicker cover and short reinforcement spacing; it is because thicker cover protect the top surface of concrete cracking and short reinforcement spacing make the through crack forming easier and earlier which uploads the concentration stress at top surface of concrete.

Crack width is an important practical parameter regarding the durability of RC structures. Figure 15 illustrates the top surface crack width development with maximum corrosion expansion displacement for reinforcement spacing $100 \mathrm{~mm}$ and three different values of cover thickness. It can be found that, the top surface crack width starts to increase at about 0.02, 0.04 and $0.06 \mathrm{~mm}$ of corrosion expansion displacement, respectively. After that, the crack width increases with corrosion development. The thicker the cover is, the later the top surface of concrete crack, which means more corrosion products are required to fracture the concrete. The sudden drops of crack with for cover thickness of $30 \mathrm{~mm}$ and $40 \mathrm{~mm}$ happen when the through crack forming. Figure 16 shows the through crack width development affected by cover thickness for reinforcement spacing $60 \mathrm{~mm}$. It can be found that, the through crack width 
increases suddenly to about $0.06 \mathrm{~mm}$ and then increases approximately linearly. Cover thickness has little effect on long-term through crack width development. But the corrosion expansion displacement to through crack forming is larger for cover thickness $20 \mathrm{~mm}$, while those for cover thickness $30 \mathrm{~mm}$ and $40 \mathrm{~mm}$ are almost same. That is because for cover thickness $20 \mathrm{~mm}$, the combined delamination and corner spalling failure happens, while for the others, the delamination failure of cover happens and no top crack forms. Therefore, for different failure modes, the critical corrosion degree to through crack forming is different. The formation of top crack provides larger deformation space for concrete, which slows down through crack propagation. Figure 17 illustrates the side surface crack width development affected by cover thickness for reinforcement spacing $60 \mathrm{~mm}$. It can be seen that, for the delamination failure of concrete cover, the thicker the cover thickness is, the later the side surface cracking occurs. These findings help structure engineer understand the cracking behaviour of concrete cover. For multiple rebars structures with a thick cover and short reinforcement spacing, the nearly horizontal cracks should be monitored more frequently, while for thin cover and long reinforcement spacing, more attention should be paid to cracks below tensile rebar.

Figure 18 shows that crack width developments at the top surface of concrete for corner bar and middle bar $(S=100 \mathrm{~mm}$ and $C=20 \mathrm{~mm})$. It can be found that, for the same non-uniform corrosion model and corrosion rate, both the two crack widths start to increase at $d_{m}$ about 0.02 $\mathrm{mm}$. However, with the corrosion degree increasing, the crack width at the top surface of middle bar is about half times of that of corner rebar. Therefore, for RC structures with multiple rebars, the top surface crack is more likely occurs at the concrete above corner or exterior rebar.

Most existing analytical models and numerical models predicting corrosion induced concrete cracking are based on uniform corrosion. To investigate the difference between nonuniform induced cracking and uniform induced cracking, crack width development under 
uniform corrosion for two cases $(S=60 \mathrm{~mm}, C=20 \mathrm{~mm}$ and $S=60 \mathrm{~mm}, C=40 \mathrm{~mm})$ are obtained as Figures 19 and 20. It should be mentioned that, the crack paths for uniform corrosion are predefined as horizontal and vertical cracks. It can be found that, for cover thickness $20 \mathrm{~mm}$, the critical steel loss ratio to top surface cracking of concrete under uniform corrosion is about two times of that of non-uniform corrosion. When the steel loss ratio is $0.6 \%$, through crack widths under non-uniform corrosion and uniform corrosion are about $0.2 \mathrm{~mm}$ and $0.02 \mathrm{~mm}$, respectively. For cover thickness $40 \mathrm{~mm}$, the side surface crack appears at steel loss ratio about $0.3 \%$ under non-uniform corrosion, while under uniform corrosion, side surface of concrete cracks at steel loss ratio $0.5 \%$. Therefore, non-uniform corrosion of rebar will fracture the concrete cover earlier and make a larger crack width than uniform corrosion of rebar.

\section{SUPERPOSITION OF CORROSION EXPANSION}

The non-uniform corrosion model derived in this paper, especially the corrosion-induced expansive displacement boundary, was based on real experimental results. This model was applied to both middle and corner bars in RC structures with multiple reinforcing bars in this study, without making differences between the corner and middle bars. This was because (1) it was assumed that chlorides, as well as other essential ions such as oxygen and moisture, penetrated through the concrete cover from one side only, e.g., the splashing wave side; and (2) there was no experimental data on double-side diffusion caused corrosion expansion which can be used to evaluate the corrosion induced displacement boundary. In fact, unlike the middle bar, the corner bar may have different corrosion expansion since chlorides might penetrate through both the top and side concrete covers. In recent years, two dimensional diffusion analysis following the Fick' law were carried out (Cao 2014, Cao and Cheung 2014, Jin, Zhang, Du and Li 2015, Muthulingam and Rao 2015). 
According to the chloride concentration distributions, it seems sensible that the corrosion model of the corner bar could be obtained by superposition of two non-uniform corrosion models. The superposition process of the non-uniform corrosion model for corner bar is described in Figure 21. However, it should be noted that the superposed boundary shape needs to be validated by experiments. In this section, the hypothetical superposition is applied to the corner bar for simulating the cracking pattern of the concrete cover. The expression for the superposed corrosion induced displacement for the corner bar can be obtained as follows:

$$
r= \begin{cases}d_{m} \quad\left(D+2 d_{0}+2 d_{m}\right)\left(D+2 d_{0}\right) & \frac{\pi}{2} \leq \theta \leq \pi \\ \frac{\sqrt{\left(2 D+4 d_{0}\right)^{2}+16 d_{m}\left(D+2 d_{0}+d_{m}\right) \cos ^{2} \theta}}{2}-\frac{D}{2}-d_{0}, & 0 \leq \theta \leq \frac{\pi}{2}, \pi \leq \theta \leq \frac{3 \pi}{2} \\ 0 & \frac{3 \pi}{2} \leq \theta \leq 2 \pi\end{cases}
$$

By using Equations (2) and (11) as the internal boundary condition of the cover structure, together with the values of reinforcement spacing $45 \mathrm{~mm}$ and fracture energy of concrete 90 $\mathrm{N} / \mathrm{m}$, the cover cracking can be simulated and the crack pattern is shown in Figure 22. The simulated cracking of the cover shows similar pattern to that presented in (Wong, Zhao, Karimi, Buenfeld and Jin 2010). It can be seen that the superimposed corrosion for corner bar can cause significant spalling failure of the cover concrete. Compared with non-superimposed corrosion for corner bar, there are two side cracks initiated at about $135^{\circ}$ and $255^{\circ}$ locations, respectively.

Figure 23 illustrates the top surface crack width and through crack width as a function of the corrosion expansion displacement $d_{m}$ for cases of superposition and non-superposition of the corner bar. It should be mentioned that the model will not converge after the surface crack width reaches about $0.348 \mathrm{~mm}$, due to severe cracking damage happening. Moreover, it has been seen that the increase rate with respect to the corrosion extent, i.e., the slop of the curve in Figure 23, of the top surface crack for superposition case is much higher than that for non- 
superposition case. The superimposed corrosion model for the corner bar has little effect on the through crack width evolution.

According to the findings, it is important to take into account the interaction of multiple corroding rebars. Having said this, it is unusual that they will (all) be subjected to the same amount of corrosion. Clearly, they will be corroding with different rates, while some may not corrode at all. This is therefore a very complex phenomenon and this paper represents a scoping research in understanding the interactive mechanism of the whole cover cracking.

\section{CONCLUSIONS}

In this paper, a numerical model has been developed to simulate the concrete cover cracking behaviour caused by non-uniform corrosion of multiple reinforcing bars. A non-uniform corrosion model of reinforcement was first formulated based on experimental results. The nonuniform corrosion expansion displacement was used as the internal boundary condition of the cover structure. Under the non-uniform expansion to the concrete structural cover, a fracture model of concrete, able to model arbitrary cracking, was established to simulate the crack initiation and propagation. Examples ware conducted to demonstrate the application of the derived model and typical cover failure patterns were extensively discussed. To validate the derived model, comparisons with the experimental results from literature were carried out.

A comprehensive parametric study was also carried out to investigate the sensitivities of some key parameters on the cover cracking of RC structures with multiple reinforcing bars. It has been found that the reinforcement spacing, cover thickness and the fracture energy of concrete can change the cover failure modes of the RC structures. Relatively short clear spacing between rebars, thick cover and low fracture energy tend to cause typical delamination failure of concrete cover while larger values of reinforcement spacing and fracture energy and thin 
cover tend to incur a top crack which leads to spalling of corner of the structure. It has also been found that with cover thickness increasing, surface cracking of concrete cover is delayed. The structural confinement effect on middle bar makes the top surface crack width above middle rebar much smaller than that above corner rebar. Compared with uniform corrosion, the non-uniform corrosion of rebar could make the concrete cover crack earlier and form larger crack width. It can be concluded that the numerical method presented in the paper can accurately simulate the cover cracking of RC structures caused by non-uniform corrosion of multiple reinforcing bars.

\section{ACKNOWLEDGEMENT}

Financial support from European Commission via the Marie Sklodowska-Curie H2020 RISE scheme under 645696 and National Key R\&D Plan of China (Grant No: 2016YFC0600803) is gratefully acknowledged. The first author would also like to thank China Scholarship Council for supporting his $\mathrm{PhD}$ research at the University of Strathclyde, UK.

\section{REFERENCES}

Al-Harthy, A.S., Stewart, M.G. \& Mullard, J., 2011. Concrete cover cracking caused by steel reinforcement corrosion. Magazine of Concrete Research, 63 (9), 655667,doi:10.1680/macr.2011.63.9.655.

Andrade, C., Molina, F.J. \& Alonso, C., 1993. Cover cracking as a function of rebar corrosion: Part 1-experiment test. Materials and Structures, 26, 453-454.

Balafas, I. \& Burgoyne, C.J., 2010. Environmental effects on cover cracking due to corrosion. Cement and Concrete Research, 40 (9), 1429-1440,doi:10.1016/j.cemconres.2010.05.003.

Bhargava, K., Ghosh, A.K., Mori, Y. \& Ramanujam, S., 2006. Model for cover cracking due to rebar corrosion in RC structures. Engineering Structures, 28 (8), 10931109,doi:10.1016/j.engstruct.2005.11.014.

Cao, C., 2014. 3D simulation of localized steel corrosion in chloride contaminated reinforced concrete. Construction and Building Materials, 72, 434443,doi:10.1016/j.conbuildmat.2014.09.030.

Cao, C. \& Cheung, M.M.S., 2014. Non-uniform rust expansion for chloride-induced pitting corrosion in rc structures. Construction and Building Materials, 51, 7581,doi:10.1016/j.conbuildmat.2013.10.042. 
Caré, S., Nguyen, Q.T., Beddiar, K. \& Berthaud, Y., 2009. Times to cracking in reinforced mortar beams subjected to accelerated corrosion tests. Materials and Structures, 43 (1-2), 107-124,doi:10.1617/s11527-009-9474-2.

Caré, S., Nguyen, Q.T., L'hostis, V. \& Berthaud, Y., 2008. Mechanical properties of the rust layer induced by impressed current method in reinforced mortar. Cement and Concrete Research, 38 (8-9), 1079-1091,doi:10.1016/j.cemconres.2008.03.016.

Chen, E. \& Leung, C.K.Y., 2015. Finite element modeling of concrete cover cracking due to non-uniform steel corrosion. Engineering Fracture Mechanics, 134, 6178,doi:10.1016/j.engfracmech.2014.12.011.

Chernin, L. \& Val, D.V., 2011. Prediction of corrosion-induced cover cracking in reinforced concrete structures. Construction and Building Materials, 25 (4), 18541869, doi:10.1016/j.conbuildmat.2010.11.074.

Du, X., Jin, L. \& Zhang, R., 2014. Modeling the cracking of cover concrete due to non-uniform corrosion of reinforcement. Corrosion Science, 89, 189202,doi:10.1016/j.corsci.2014.08.025.

Farid Uddin, A.K.M., Numata, K., Shimasaki, J., Shigeishi, M. \& Ohtsu, M., 2004. Mechanisms of crack propagation due to corrosion of reinforcement in concrete by AEsigma and bem. Construction and Building Materials, 18 (3), 181188,doi:10.1016/j.conbuildmat.2003.10.007.

Gálvez, J.C., Cendón, D.A. \& Planas, J., 2002. Influence of shear parameters on mixed-mode fracture of concrete. International Journal of Fracture, 118 (2), 163189,doi:10.1023/a:1022883132117.

Guzmán,S., Gálvez, J.C., Sancho, J.M., 2011. Cover cracking of reinforced concrete due to rebar corrosion induced by chloride penetration, Cement and Concrete Research, 41, 893902, doi: $10.1016 /$ j.cemconres.2011.04.008

Hillerborg, A., Modeer, M. \& Petersson, P.E., 1976. Analysis of crack formation and crack growth in concrete by means of fracture mechanics and finite elements. Cement and Concrete Research, 6 (6), 773-781.

Jang, B.S. \& Oh, B.H., 2010. Effects of non-uniform corrosion on the cracking and service life of reinforced concrete structures. Cement and Concrete Research, 40 (9), 14411450,doi:10.1016/j.cemconres.2010.03.018.

Jin, L., Zhang, R., Du, X. \& Li, Y., 2015. Investigation on the cracking behavior of concrete cover induced by corner located rebar corrosion. Engineering Failure Analysis, 52, 129143,doi:10.1016/j.engfailanal.2015.03.019.

Koch Gh, Brongers Ph, Thompson Ng, Virmani Yp \& Jh, P., 2002. Corrsion costs and prevention strategies in the united states. Washington DC: Federal Highway Administration.

Li, C.Q., 2003. Life-cycle modelling of corrosion-affected concrete structures: Propagation. Journal of Structural Engineering-ASCE 129 (6), 753-761,doi: 10.1061/(ASCE)07339445(2003)129:6(753).

Li, C.Q., 2005. Time dependent reliability analysis of the serviceability of corrosion affected concrete structures. International Journal of Materials and Structural Reliability, 3 (2), 105-116.

Li, C.Q. \& Yang, S.T., 2011. Prediction of concrete crack width under combined reinforcement corrosion and applied load. Journal of Engineering Mechanics-ASCE, 137 (11), $722-$ 731,doi:10.1061/(ASCE)em.1943-7889.0000289.

Liu, Y. \& Weyers, R.E., 1998. Modelling the time-to-corrosion cracking in chloride contaminated reinforced concrete structures. ACI Materials Journal, 95 (6), 675-681. 
Mergheim, J., Kuhl, E. \& Steinmann, P., 2005. A finite element method for the computational modelling of cohesive cracks. International Journal for Numerical Methods in Engineering, 63 (2), 276-289,doi:10.1002/nme.1286.

Mullard, J.A. \& Stewart, M.G., 2011. Corrosion-induced cover cracking: New test data and predictive models. ACI Structural Journal, 108 (1), 71-79.

Muthulingam, S. \& Rao, B.N., 2015. Non-uniform corrosion states of rebar in concrete under chloride environment. Corrosion Science, 93, 267-282,doi:10.1016/j.corsci.2015.01.031.

Muthulingam, S., 2016. Gaussian descriptions of corrosion initiation in steel bars of fly ash concrete elements. Structure and Infrastructure Engineering, 119,doi:10.1080/15732479.2016.1265990.

Pantazopoulou, S.J. \& Papoulia, K.D., 2001. Modeling cover-cracking due to reinforcement corrosion in RC structures. Journal of Engineering Mechanics-ASCE., 127, 342, doi: 10.1061/(ASCE)0733-9399(2001)127:4(342).

Sanz, B., Planas, J. \& Sancho, J.M., 2013. An experimental and numerical study of the pattern of cracking of concrete due to steel reinforcement corrosion. Engineering Fracture Mechanics, 114, 26-41,doi:10.1016/j.engfracmech.2013.10.013.

Šavija, B., Luković, M., Pacheco, J. \& Schlangen, E., 2013. Cracking of the concrete cover due to reinforcement corrosion: A two-dimensional lattice model study. Construction and Building Materials, 44, 626-638,doi:10.1016/j.conbuildmat.2013.03.063.

Shilang, X., 1999. Determination of parameters in the bilinear,reinhardt's nonlinear and exponentially non-linear softening curves and their physical meanings. Stuttgart: University of Stuttgart, 410-424.

Timoshenko, S.P. \& Goodier, J.N., 1970. Theory of elasticity, 3rd ed. Singapore.

Tran, K.K., Nakamura, H., Kawamura, K. \& Kunieda, M., 2011. Analysis of crack propagation due to rebar corrosion using RBSM. Cement and Concrete Composites, 33 (9), 906917,doi:10.1016/j.cemconcomp.2011.06.001.

Val;, D.V., Chernin;, L. \& Stewart, M.G., 2009. Experimental and numerical investigation of corrosion-induced cover cracking in reinforced concrete structures. Journal of Structural Engineering, 135 (4), 10,doi:10.1061//ASCE/0733-9445/2009/135:4/376.

Vu, K., Stewart, M.G. \& Mullard, J., 2005. Corrosion-induced cracking: Experimental data and predictive models. ACI Structural Journal, 102 (5), 719-726.

Wong, H.S., Zhao, Y.X., Karimi, A.R., Buenfeld, N.R. \& Jin, W.L., 2010. On the penetration of corrosion products from reinforcing steel into concrete due to chloride-induced corrosion. Corrosion Science, 52 (7), 2469-2480, doi:10.1016/j.corsci.2010.03.025.

$\mathrm{Xu}, \mathrm{S}$. \& Zhang, X., 2008. Determination of fracture parameters for crack propagation in concrete using an energy approach. Engineering Fracture Mechanics, 75 (15), 42924308,doi:10.1016/j.engfracmech.2008.04.022.

Yang, S., Li, K. \& Li, C. Q., 2017a. Analytical model for non-uniform corrosion-induced concrete cracking. Magazine of Concrete Research, 1-10,doi:10.1680/jmacr.17.00153.

Yang, S., Li, K. \& Li, C. Q., 2017b. Numerical determination of concrete crack width for corrosion-affected concrete structures, Computers \& Structures, doi: 10.1016/j.compstruc.2017.07.016.

Yang, Z.J., Su, X. T., Chen, J. F., Liu, G. H.,2009. Monte Carlo simulation of complex cohesive fracture in random heterogeneous quasi-brittle materials. International Journal of Solids and Structures, 46(17), 3222-3234, doi:10.1016/j.ijsolstr.2009.04.013.

Ye H, Jin N, Fu C, Jin X., 2017. Rust distribution and corrosion-induced cracking patterns of corner-located rebar in concrete cover. Construction and Building Materials, 156:68491,doi: https://doi.org/10.1016/j.conbuildmat.2017.09.033 
Yuan, Y. \& Ji, Y., 2009. Modeling corroded section configuration of steel bar in concrete structure. Construction and Building Materials, 23 (6), 24612466,doi:10.1016/j.conbuildmat.2008.09.026.

Zhang, J., Ling, X. \& Guan, Z., 2017. Finite element modeling of concrete cover crack propagation due to non-uniform corrosion of reinforcement. Construction and Building Materials, 132, 487-499, doi:10.1016/j.conbuildmat.2016.12.019.

Zhao, Y., Karimi, A.R., Wong, H.S., Hu, B., Buenfeld, N.R. \& Jin, W., 2011. Comparison of uniform and non-uniform corrosion induced damage in reinforced concrete based on a gaussian description of the corrosion layer. Corrosion Science, 53 (9), 28032814,doi:10.1016/j.corsci.2011.05.017. 


\section{LIST OF TABLES}

1. Geometric parameters values

2. Mechanical variables values

3. Additional variables values used for comparison and validation 
Table 1 Geometric parameters values

\begin{tabular}{c|c|c}
\hline Description & Symbol & Values \\
\hline Cover thickness & $C$ & $20 \mathrm{~mm}$ \\
Clear spacing of steel bars & $S$ & $60 \mathrm{~mm}$ \\
Diameter of steel bars & $D$ & $12 \mathrm{~mm}$ \\
Height of RC & $H$ & $400 \mathrm{~mm}$ \\
\hline
\end{tabular}


Table 2 Mechanical variables values

\begin{tabular}{|c|c|c|c|}
\hline Description & Symbol & Values & Sources \\
\hline $\begin{array}{c}\text { Effective modulus of } \\
\text { elasticity }\end{array}$ & $E_{e f}$ & $18.82 \mathrm{GPa}$ & Li (2003) \\
\hline Poisson's ratio & $v_{c}$ & 0.18 & Li (2003) \\
\hline Shear modulus & $G$ & $E /[2(1+v)]$ & $\begin{array}{l}\text { Timoshenko and } \\
\text { Goodier (1970) }\end{array}$ \\
\hline Tensile strength & $f_{t}^{\prime}$ & $5.725 \mathrm{MPa}$ & Li (2003) \\
\hline Fracture energy & $G_{f}$ & $120 \mathrm{~N} / \mathrm{m}$ & Xu (1999\&2008) \\
\hline Molecular weight ratio & $\alpha_{\text {rust }}$ & 0.57 & $\begin{array}{c}\text { Liu and Weyers } \\
\text { (1998) }\end{array}$ \\
\hline Density of rust & $\rho_{\text {rust }}$ & $3.60 \mathrm{mg} / \mathrm{mm}^{3}$ & $\begin{array}{c}\text { Liu and Weyers } \\
\text { (1998) }\end{array}$ \\
\hline Density of steel & $\rho_{s t}$ & $7.85 \mathrm{mg} / \mathrm{mm}^{3}$ & $\begin{array}{c}\text { Liu and Weyers } \\
\text { (1998) }\end{array}$ \\
\hline
\end{tabular}


Table 3 Additional variables values used for comparison and validation

\begin{tabular}{c|c|c}
\hline Description & Symbol & Values \\
Top cover thickness & $C_{T}$ & $10 \mathrm{~mm}$ \\
Edge cover thickness & $C_{E}$ & $20 \mathrm{~mm}$ \\
Diameter of steel bars & $D$ & $10 \mathrm{~mm}$ \\
Length of RC & $L$ & $100 \mathrm{~mm}$ \\
Height of RC & $H$ & $100 \mathrm{~mm}$ \\
Effective modulus of & $E_{e f}$ & $18.82 \mathrm{GPa}$ \\
elasticity & $v_{c}$ & 0.18 \\
Poisson's ratio & $f_{t}^{\prime}$ & $5.725 \mathrm{MPa}$ \\
Tensile strength & $G_{f}$ & $120 \mathrm{~N} / \mathrm{m}$ \\
\hline Fracture energy & & \\
\hline
\end{tabular}




\section{LIST OF FIGURES}

1. Non-uniform corrosion model

2. Constitutive relationship of concrete in tension

3. Insertion process of cohesive elements: (a) initial mesh; (b) inserted cohesive element based on newly created nodes; and (c) mesh after insertion of cohesive elements

4. Configuration of the reinforced concrete with multi tension bars

5. Typical meshing arrangements for half of the structure

6. Determination of residual stress in terms of the damage parameter $D$

7. Two typical cracking mechanisms

8. Illustration of the maximum principal stress under various levels of corrosion for the cracking mechanism $1(C=40 \mathrm{~mm})$

9. Illustration of the maximum principal stress under various levels of corrosion for the cracking mechanism $1(C=20 \mathrm{~mm})$

10. Corrosion expansion displacement $d_{m}$ as a function of steel loss ratio

11. Experimental verification of the crack width from the developed model

12. Crack patterns for different combinations of clear spacing and fracture energy $(C=20$ $\mathrm{mm})$

13. Displacement of the first cohesive elements of the potential top and side crack as a function of $d_{m}(C=20 \mathrm{~mm}$ and $S=30 \mathrm{~mm})$

14. Crack patterns for different combinations of cover thickness and spacing $\left(G_{f}=120 \mathrm{~N} / \mathrm{mm}\right)$

15. Top crack width development affected by cover thickness ( $S=100 \mathrm{~mm}$ and $G_{f}=120 \mathrm{~N} / \mathrm{mm}$ )

16. Through crack width development affected by cover thickness ( $S=60 \mathrm{~mm}$ and $G_{f}=120$ $\mathrm{N} / \mathrm{mm})$

17. Side crack width development affected by cover thickness ( $S=60 \mathrm{~mm}$ and $G_{f}=120 \mathrm{~N} / \mathrm{mm}$ ) 
18. Structural confinement of crack width for middle bar for non-uniform corrosion $(S=100$ $\mathrm{mm}, C=20 \mathrm{~mm}$ and $\left.G_{f}=120 \mathrm{~N} / \mathrm{mm}\right)$

19. Crack width as a function of steel loss ratio under uniform corrosion and non-uniform corrosion for $S=60 \mathrm{~mm}, C=20 \mathrm{~mm}$ and $G_{f}=120 \mathrm{~N} / \mathrm{mm}$

20. Crack width as a function of steel loss ratio under uniform corrosion and non-uniform corrosion for $S=60 \mathrm{~mm}, C=40 \mathrm{~mm}$ and $G_{f}=120 \mathrm{~N} / \mathrm{mm}$

21. Superposition of the non-uniform corrosion model for the corner bar

22. Typical crack pattern caused by superposed corrosion model for the corner bar

23. Crack width as a function of corrosion expansion displacement for cases of superposition and non-superposition of the corner bar 


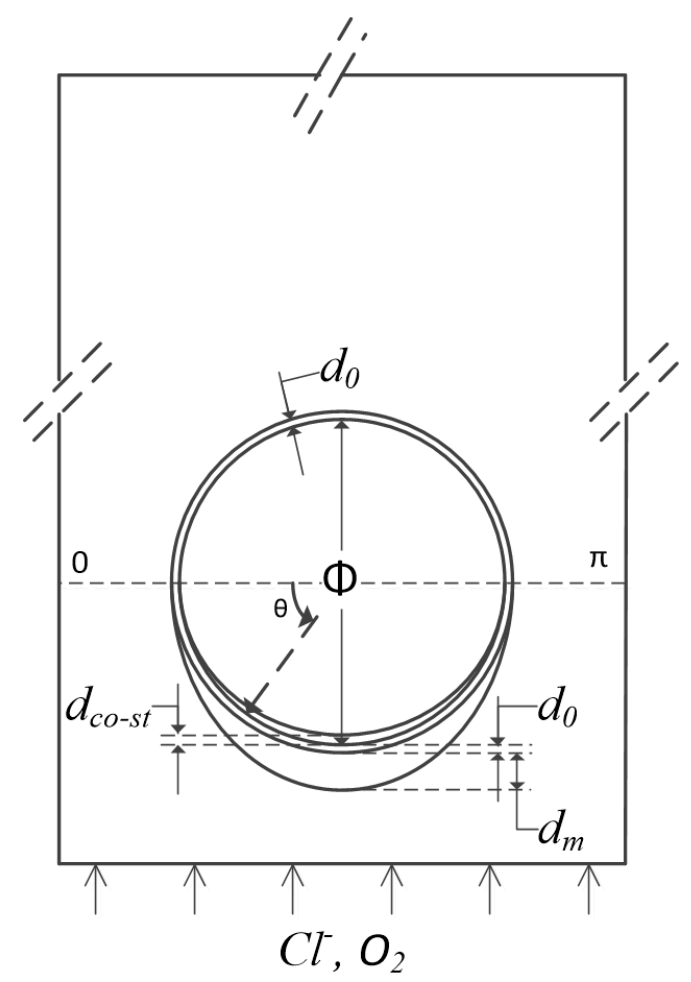

Figure 1 Non-uniform corrosion model 


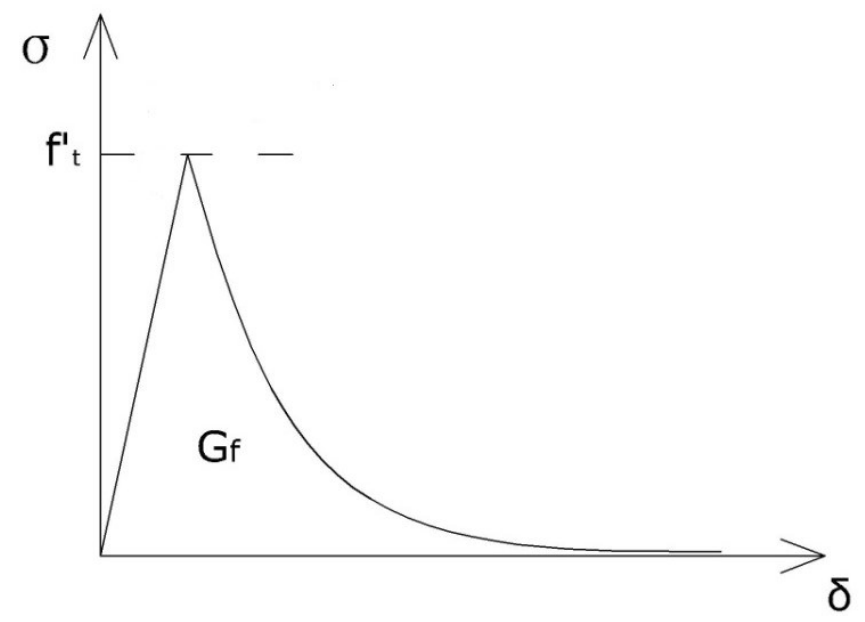

Figure 2 Constitutive relationship of concrete in tension 


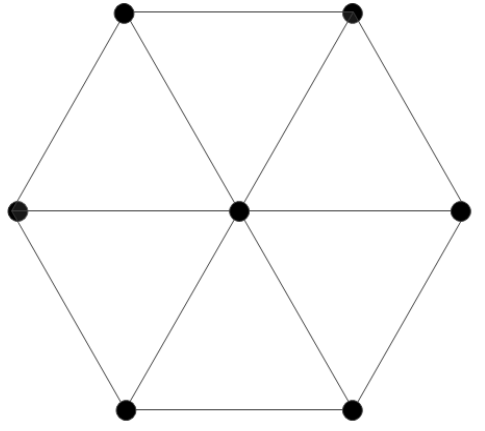

(a)

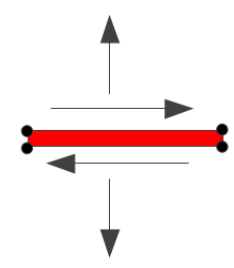

(b)

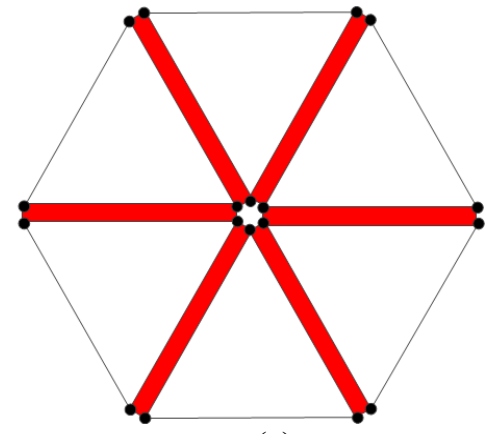

(c)

Figure 3 Insertion process of cohesive elements: (a) initial mesh; (b) inserted cohesive element based on newly created nodes; and (c) mesh after insertion of cohesive elements 


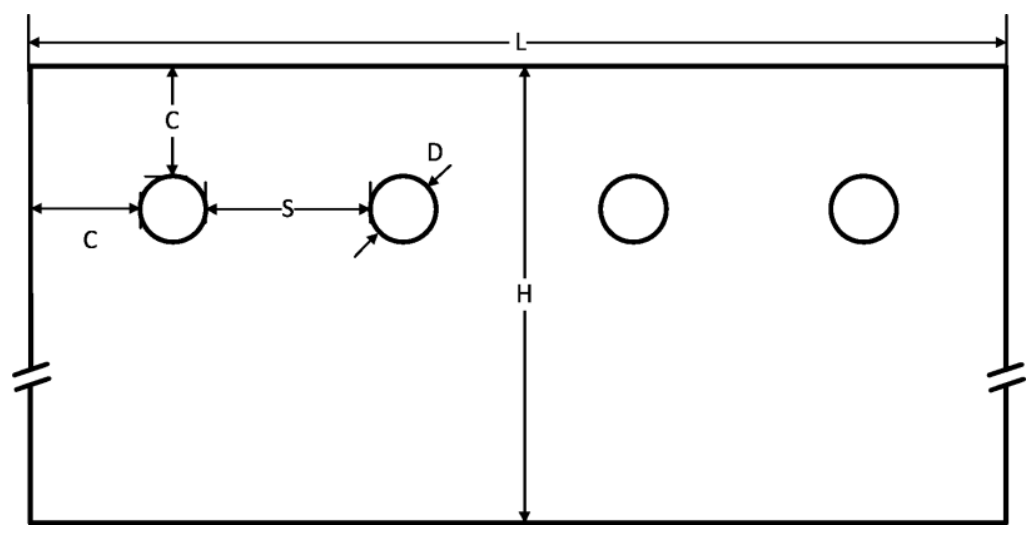

Figure 4 Configuration of the reinforced concrete with multi tension bars 


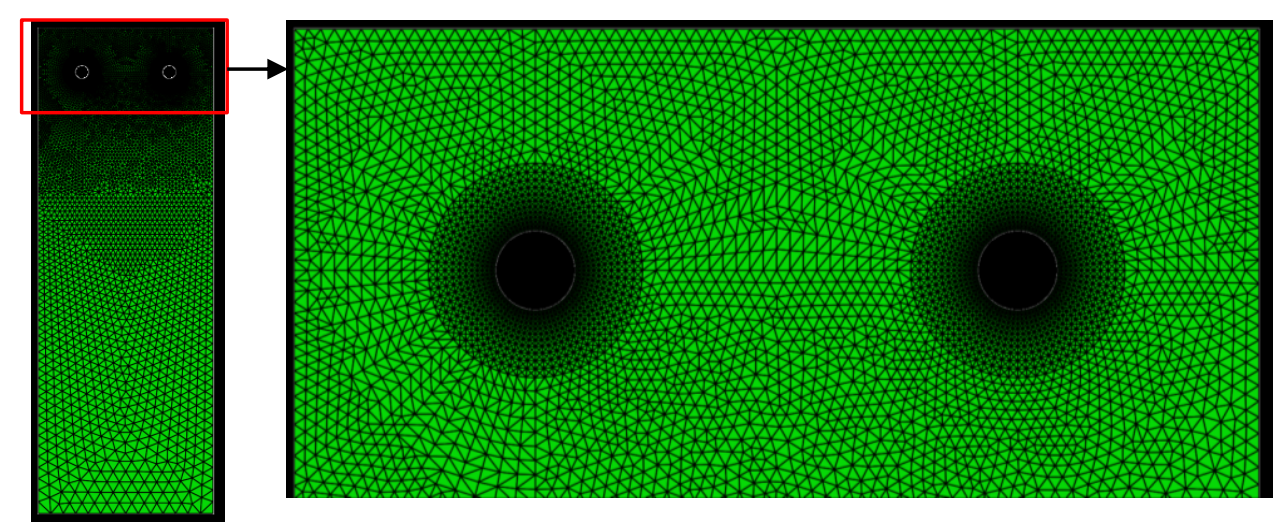

Figure 5 Typical meshing arrangements for half of the structure 


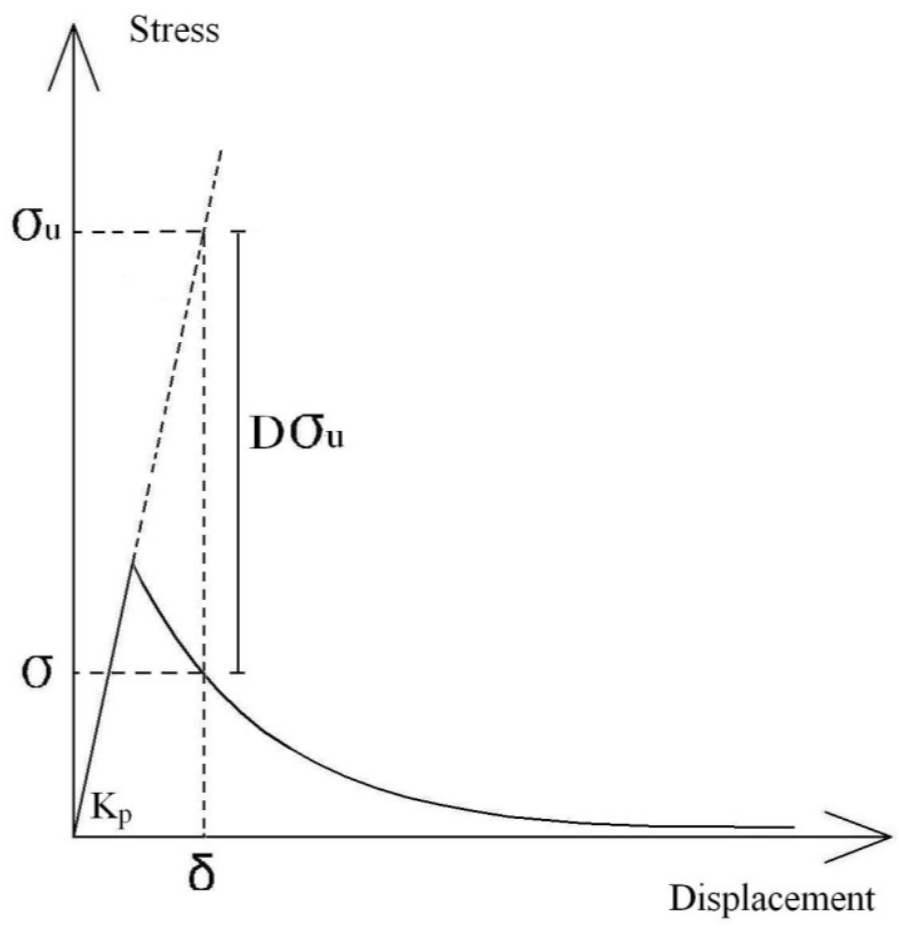

Figure 6 Determination of residual stress in terms of the damage parameter $D$ 


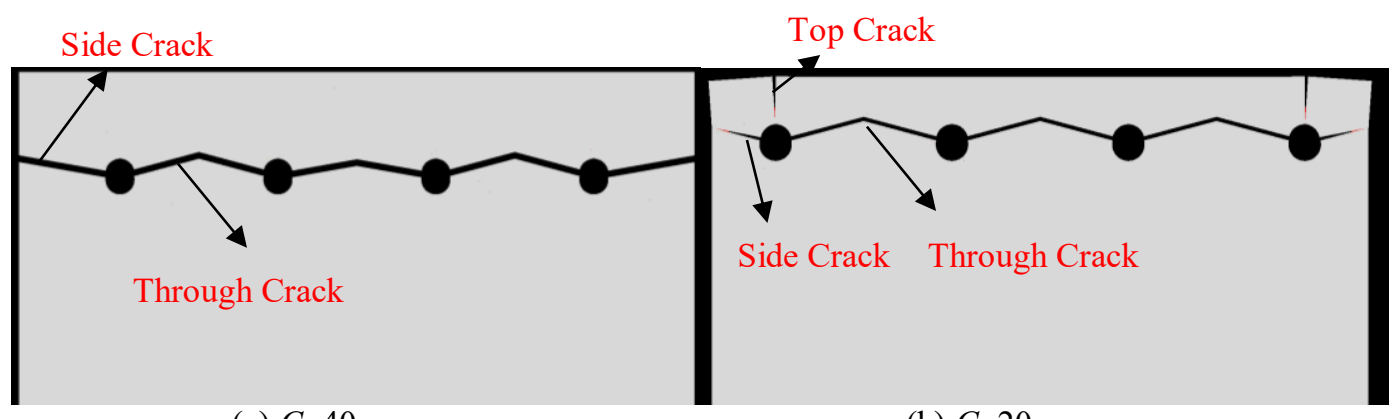

(a) $C=40 \mathrm{~mm}$

(b) $C=20 \mathrm{~mm}$

Figure 7 Two typical cracking mechanisms 

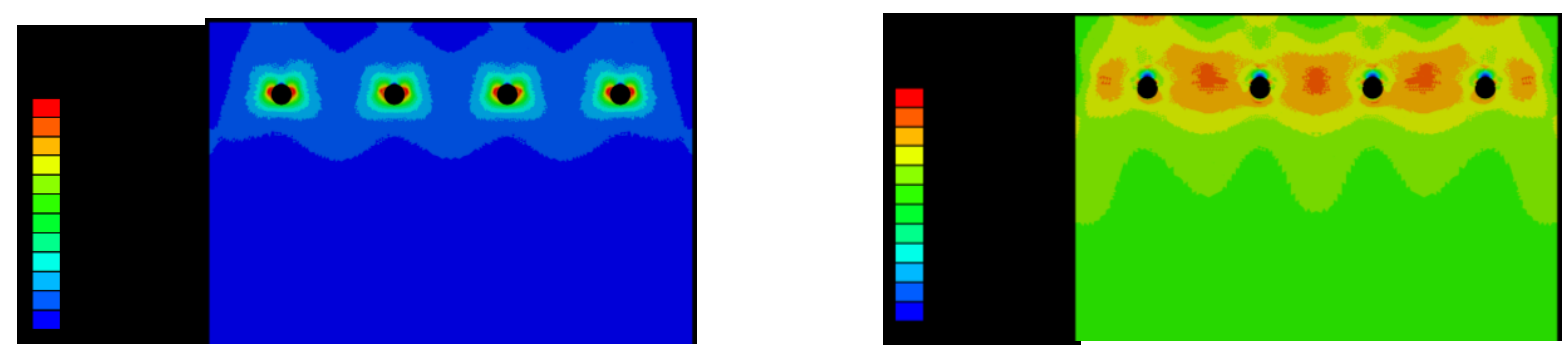

(1) $d_{m}=5.51 \mu \mathrm{m}$

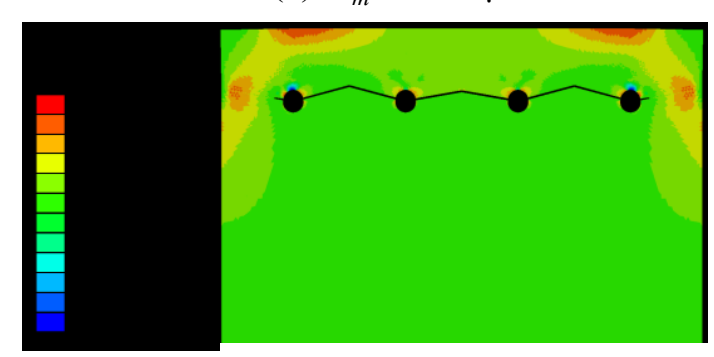

(2) $d_{m}=55.00 \mu \mathrm{m}$

(3) $d_{m}=64.32 \mu \mathrm{m} \quad$ Deformation Scale $=10$

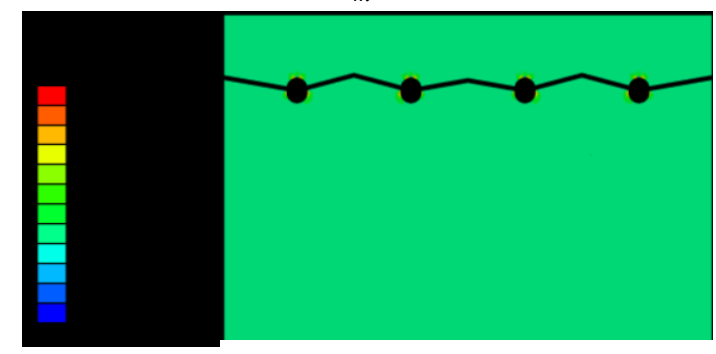

(4) $d_{m}=151.64 \mu \mathrm{m}$

Figure 8 Illustration of the maximum principal stress under various levels of corrosion for the cracking mechanism $1(C=40 \mathrm{~mm})$ 


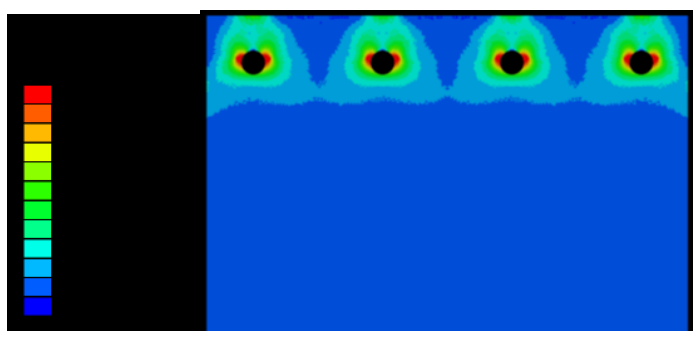

(1) $d_{m}=5.54 \mu \mathrm{m}$

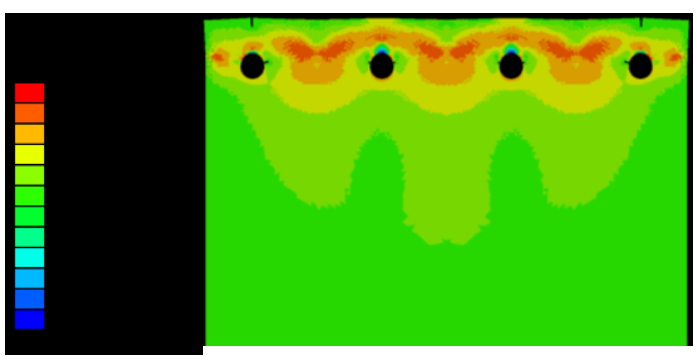

(3) $d_{m}=60.60 \mu \mathrm{m}$

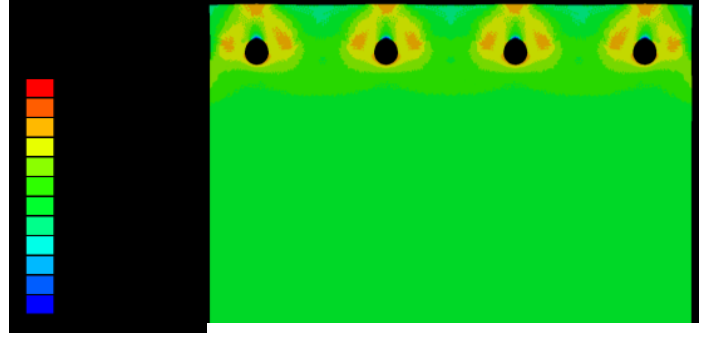

(2) $d_{m}=27.64 \mu \mathrm{m}$

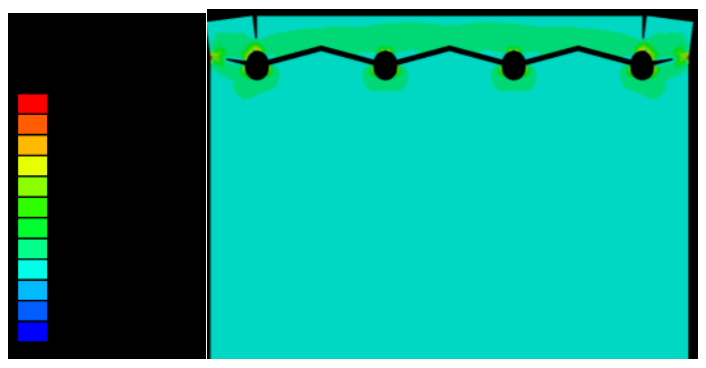

(4) $d_{m}=160.67 \mu \mathrm{m}$

Deformation Scale $=10$

Figure 9 Illustration of the maximum principal stress under various levels of corrosion for the cracking mechanism $2(C=20 \mathrm{~mm})$ 


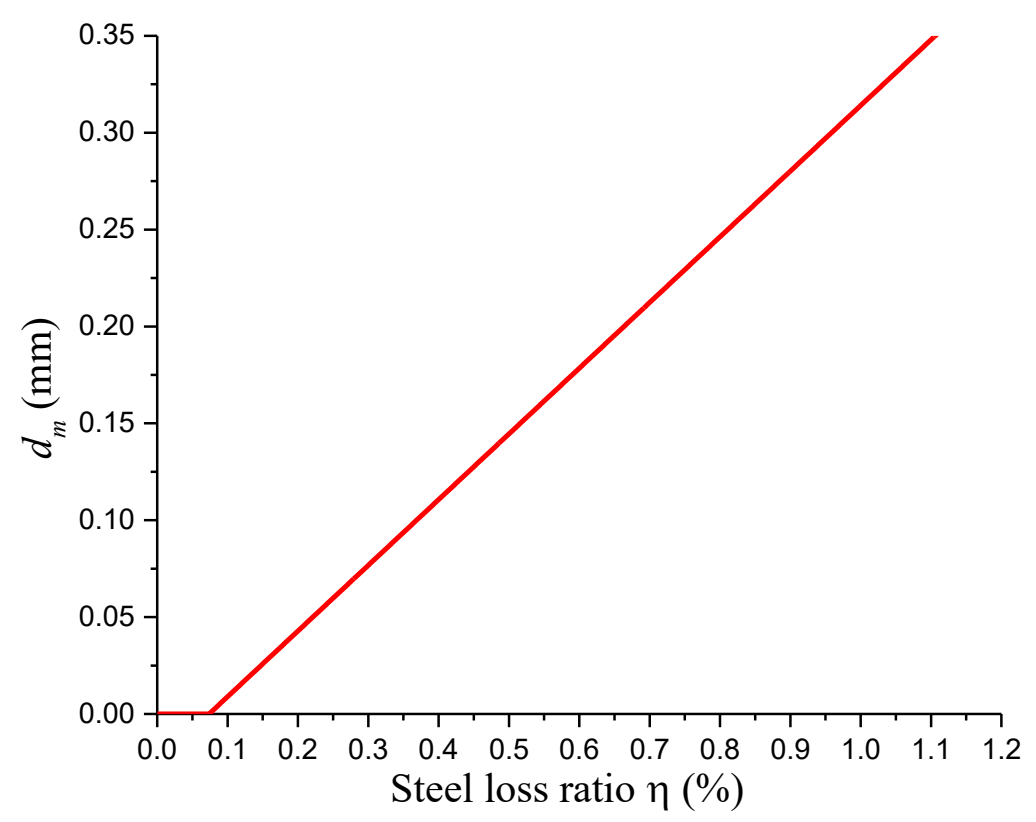

Figure 10 Corrosion expansion displacement $d_{m}$ as a function of steel loss ratio 


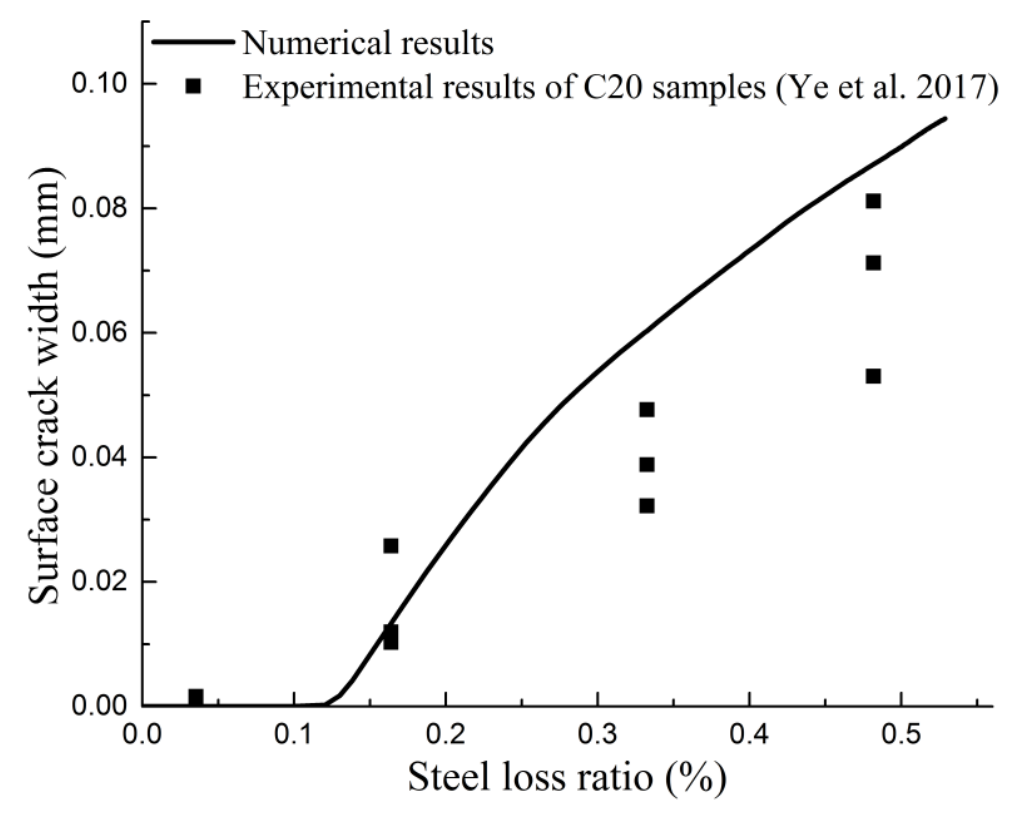

Figure 11 Experimental verification of the crack width from the developed model 


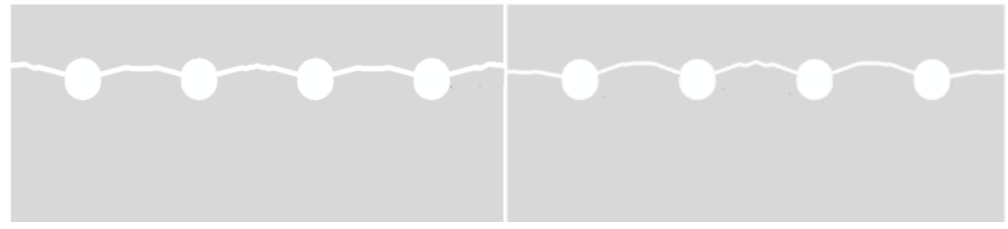

(a) $\mathrm{S}=30 \mathrm{~mm}, G_{f}=60 \mathrm{~N} / \mathrm{m}$

(b) $\mathrm{S}=30 \mathrm{~mm}, G_{f}=90 \mathrm{~N} / \mathrm{m}$

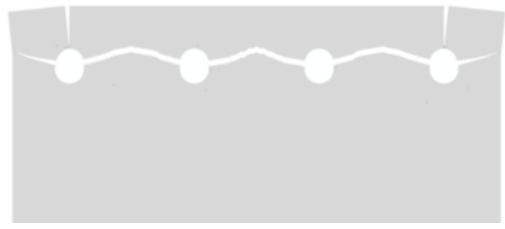

(d) $\mathrm{S}=45 \mathrm{~mm}, G_{f}=60 \mathrm{~N} / \mathrm{m}$

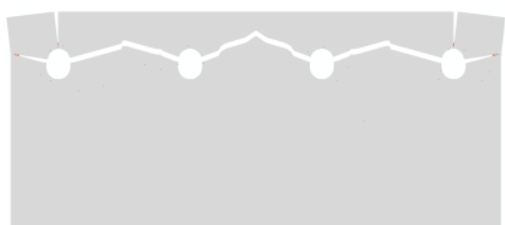

(g) $\mathrm{S}=60 \mathrm{~mm}, G_{f}=60 \mathrm{~N} / \mathrm{m}$ (e) $\mathrm{S}=45 \mathrm{~mm}, G_{f}=90 \mathrm{~N} / \mathrm{m}$

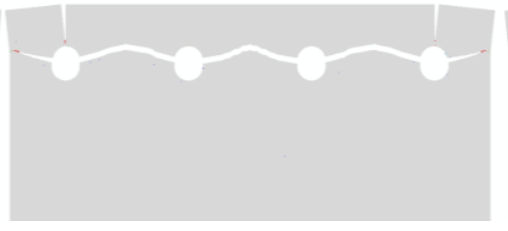

(h) $\mathrm{S}=60 \mathrm{~mm}, G_{f}=90 \mathrm{~N} / \mathrm{m}$

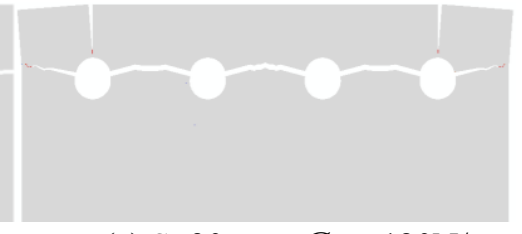

(c) $\mathrm{S}=30 \mathrm{~mm}, G_{f}=120 \mathrm{~N} / \mathrm{m}$

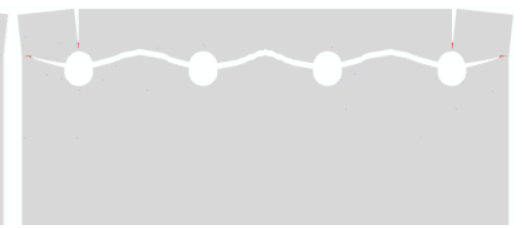

(f) $\mathrm{S}=45 \mathrm{~mm}, G_{f}=120 \mathrm{~N} / \mathrm{m}$

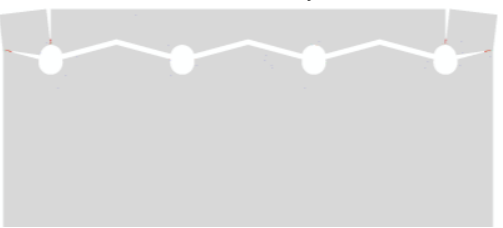

(i) $\mathrm{S}=60 \mathrm{~mm}, G_{f}=120 \mathrm{~N} / \mathrm{m}$

Figure 12 Crack patterns for different combinations of clear spacing and fracture energy $(C=20 \mathrm{~mm})$ 


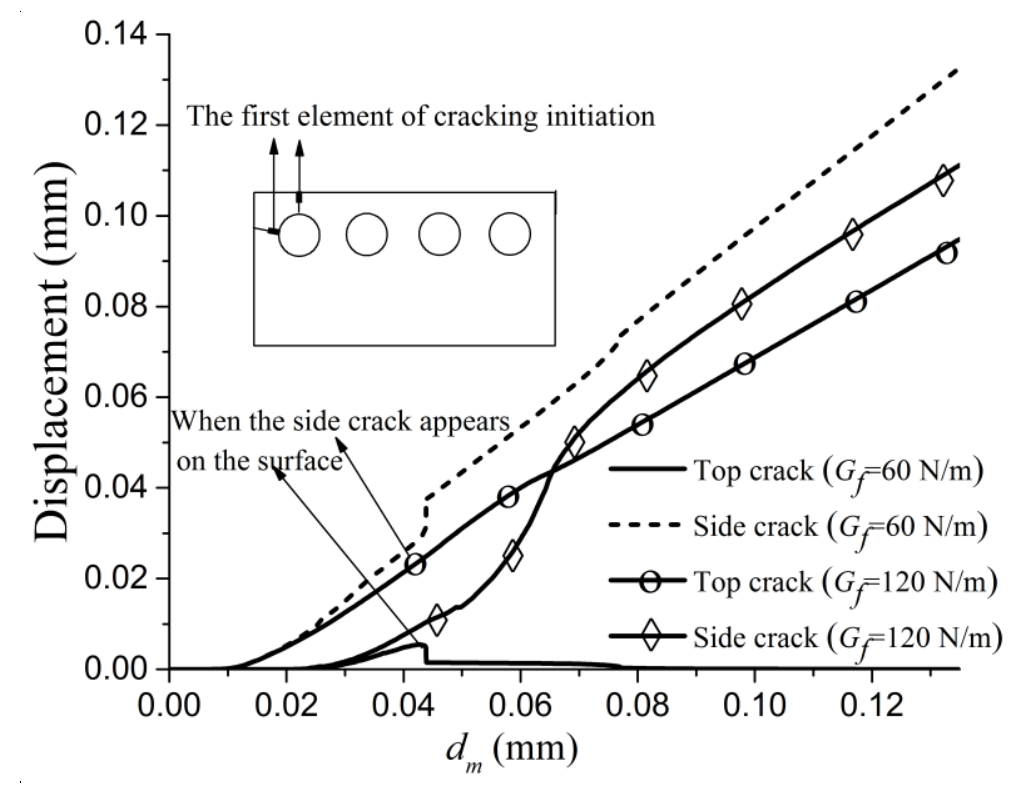

Figure 13 Displacement of the first cohesive elements of the potential top and side crack as a function of $d_{m}(C=20 \mathrm{~mm}$ and $S=30 \mathrm{~mm})$ 


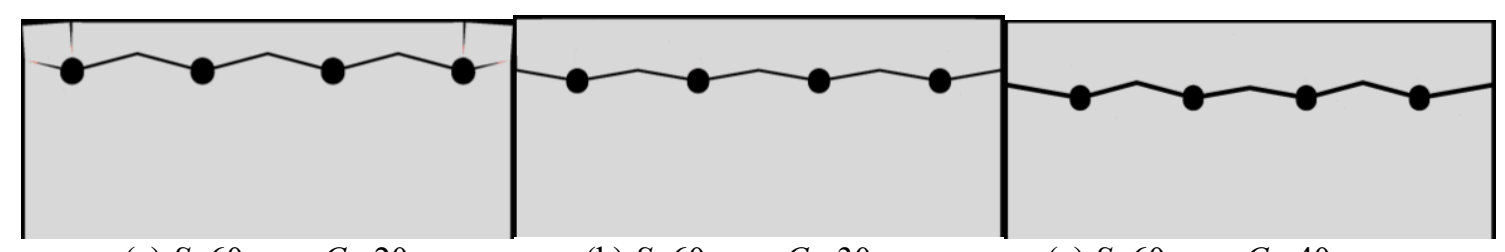

(a) $S=60 \mathrm{~mm}, C=20 \mathrm{~mm}$

(b) $S=60 \mathrm{~mm}, C=30 \mathrm{~mm}$

(c) $S=60 \mathrm{~mm}, C=40 \mathrm{~mm}$

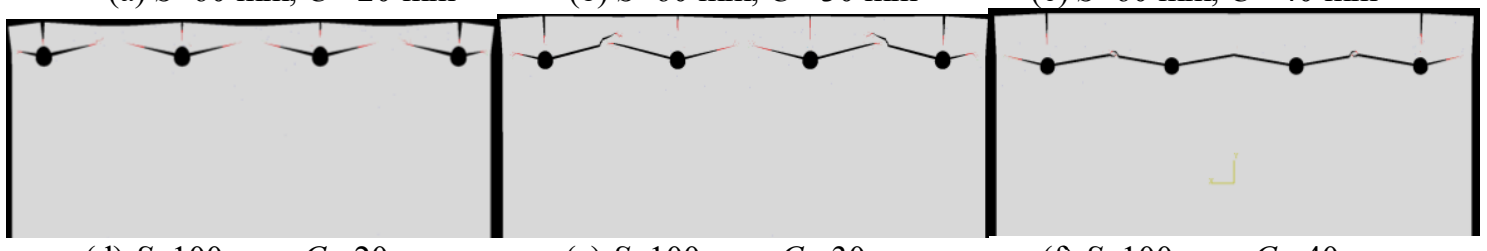

(d) $S=100 \mathrm{~mm}, C=20 \mathrm{~mm}$

(e) $S=100 \mathrm{~mm}, C=30 \mathrm{~mm}$

(f) $S=100 \mathrm{~mm}, C=40 \mathrm{~mm}$

Figure 14 Crack patterns for different combinations of cover thickness and spacing $\left(G_{f}=120\right.$ $\mathrm{N} / \mathrm{m})$ 


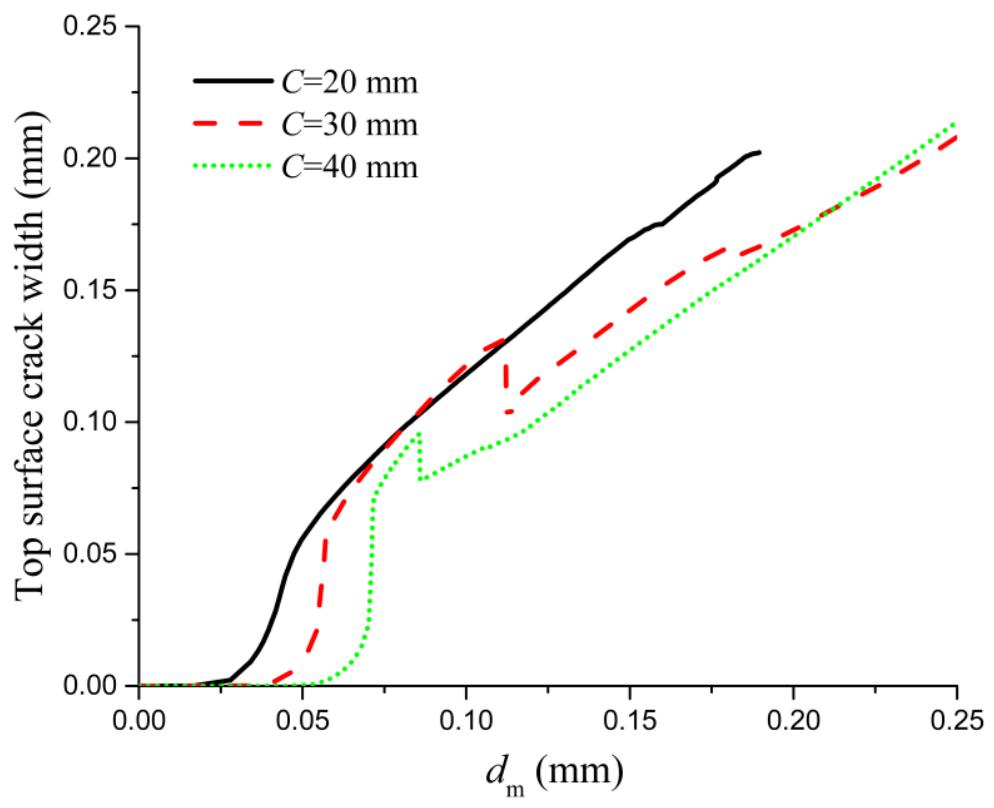

Figure 15 Top crack width development affected by cover thickness $\left(S=100 \mathrm{~mm}\right.$ and $G_{f}=120$ $\mathrm{N} / \mathrm{mm}$ ) 


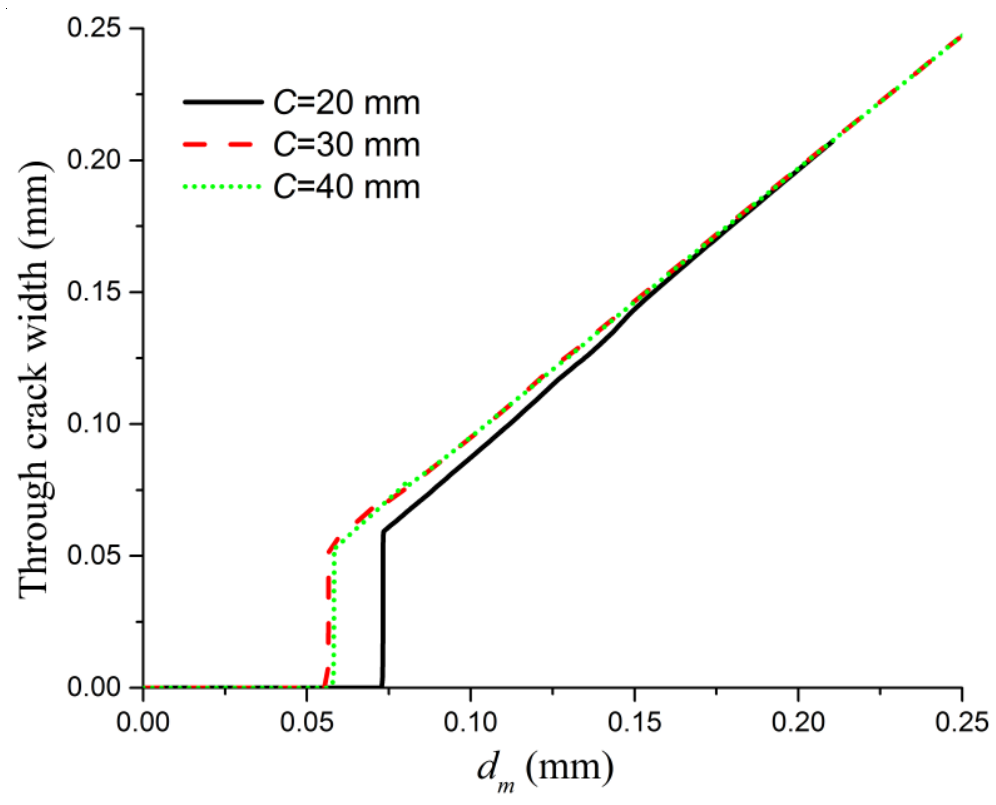

Figure 16 Through crack width development affected by cover thickness $(S=60 \mathrm{~mm}$ and $\left.G_{f}=120 \mathrm{~N} / \mathrm{mm}\right)$ 


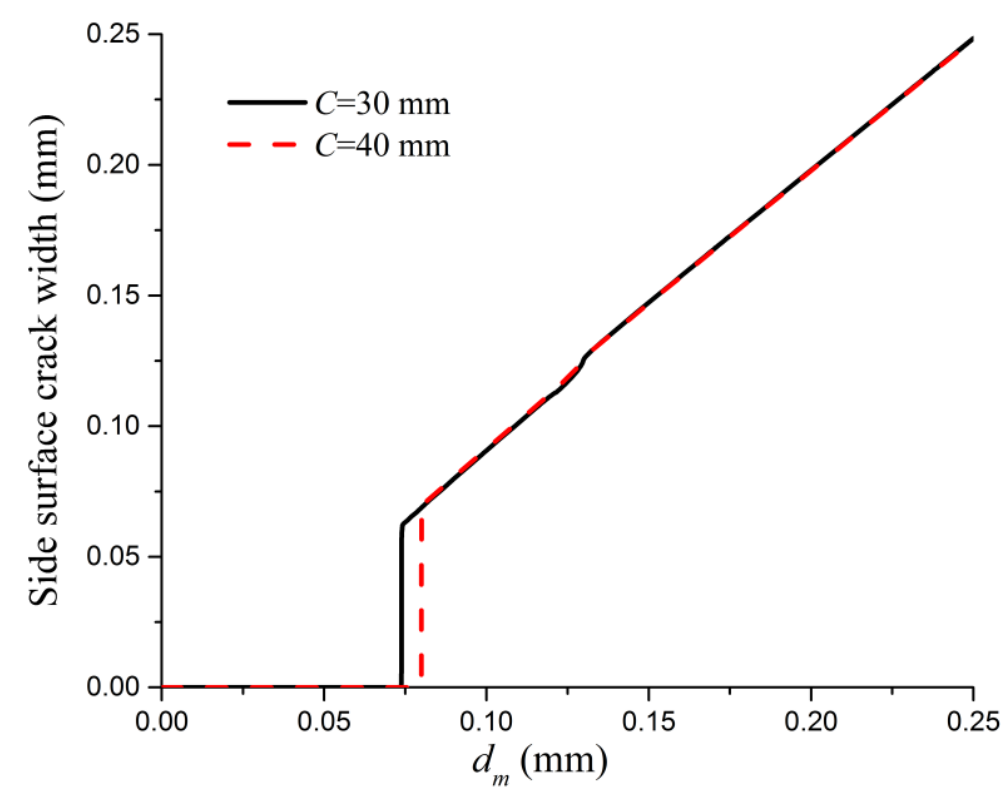

Figure 17 Side crack width development affected by cover thickness ( $S=60 \mathrm{~mm}$ and $G_{f}=120$ $\mathrm{N} / \mathrm{mm}$ ) 


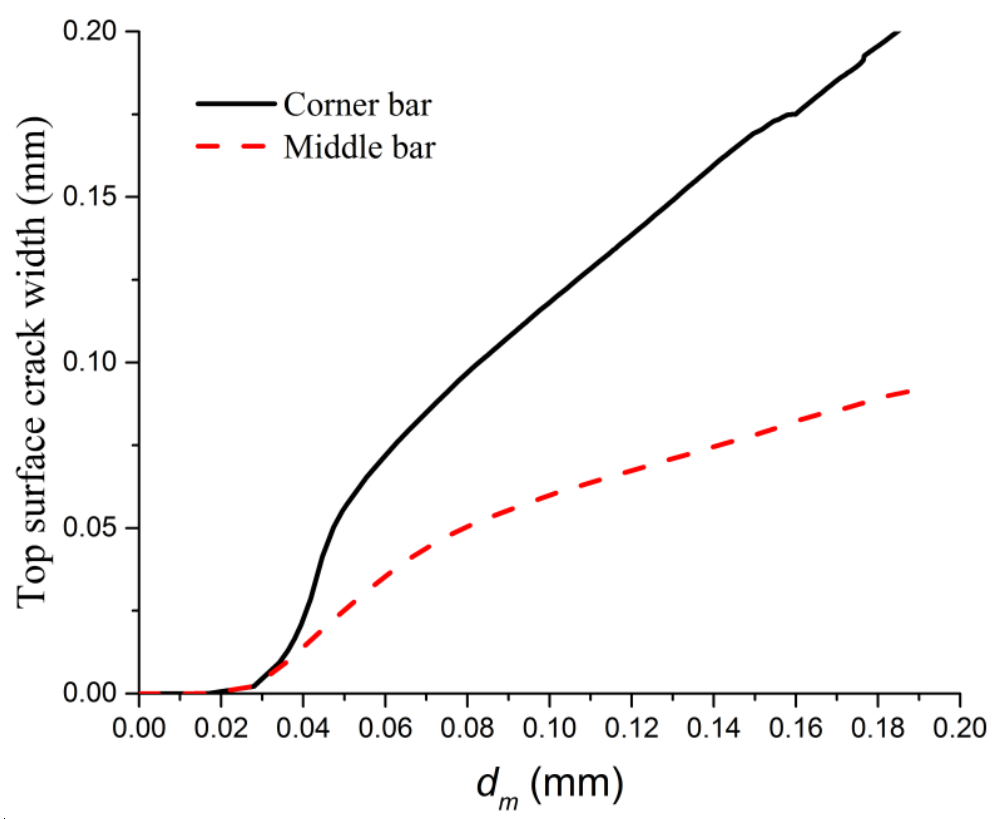

Figure 18 Structural confinement of crack width for middle bar for non-uniform corrosion $\left(S=100 \mathrm{~mm}, C=20 \mathrm{~mm}\right.$ and $\left.G_{f}=120 \mathrm{~N} / \mathrm{mm}\right)$ 


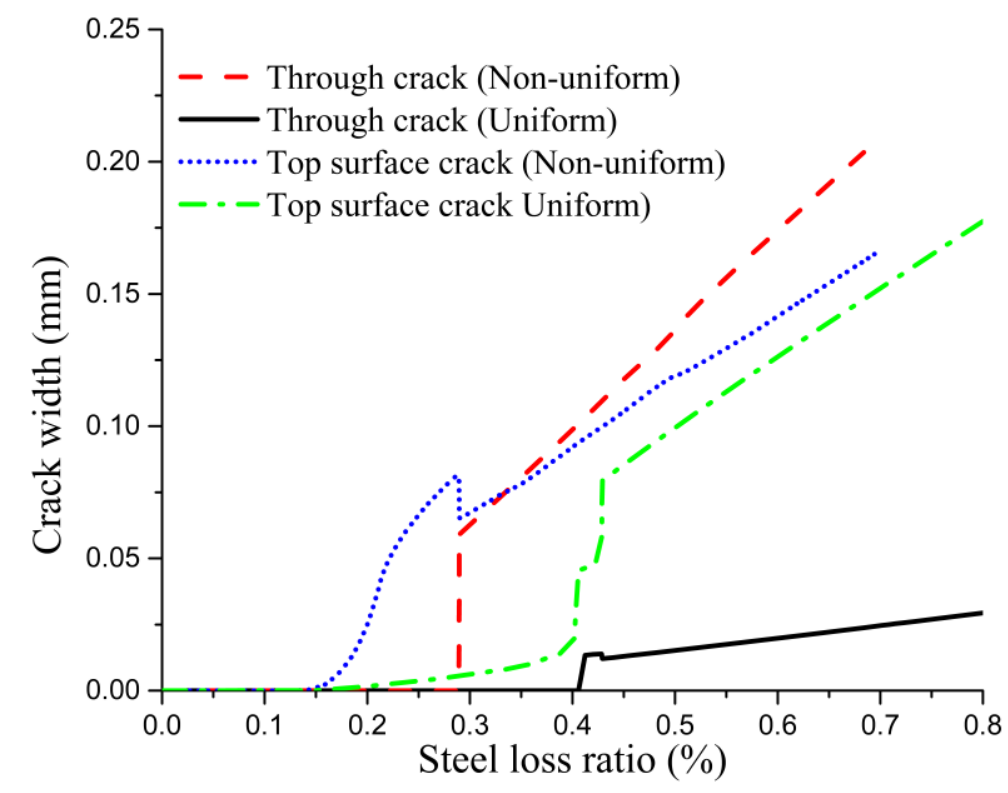

Figure 19 Crack width as a function of steel loss ratio under uniform corrosion and nonuniform corrosion for $S=60 \mathrm{~mm}, C=20 \mathrm{~mm}$ and $G_{f}=120 \mathrm{~N} / \mathrm{mm}$ 


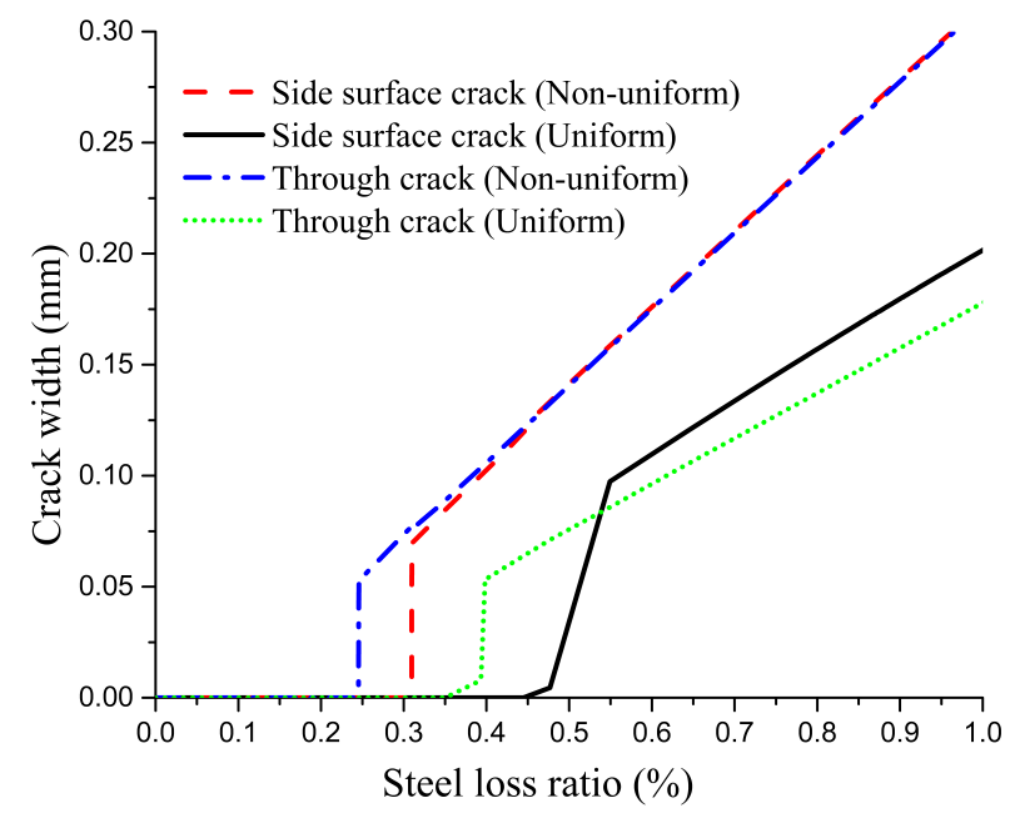

Figure 20 Crack width as a function of steel loss ratio under uniform corrosion and nonuniform corrosion for $S=60 \mathrm{~mm}, C=40 \mathrm{~mm}$ and $G_{f}=120 \mathrm{~N} / \mathrm{mm}$ 


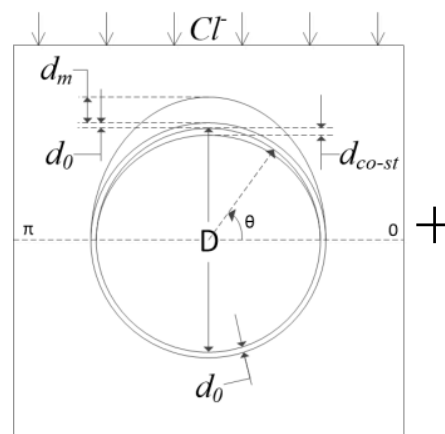

(a)

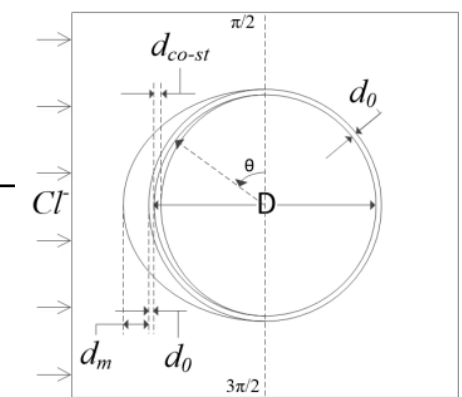

(b)

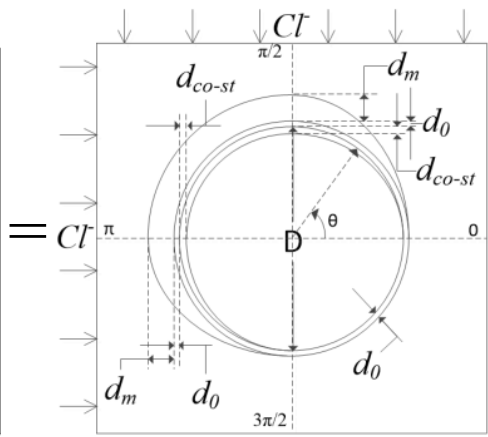

(c)

Figure 21 Superposition of the non-uniform corrosion model for the corner bar 


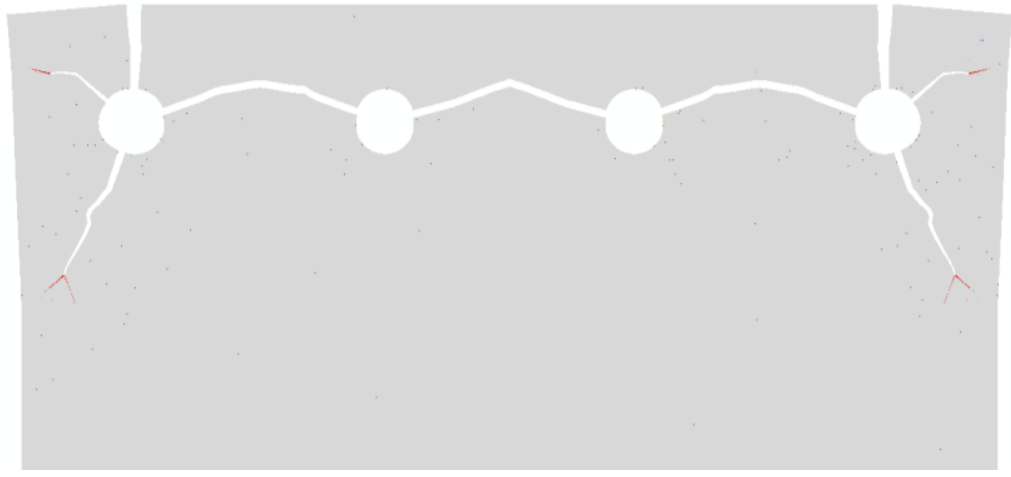

Figure 22 Typical crack pattern caused by superposed corrosion model for the corner bar 


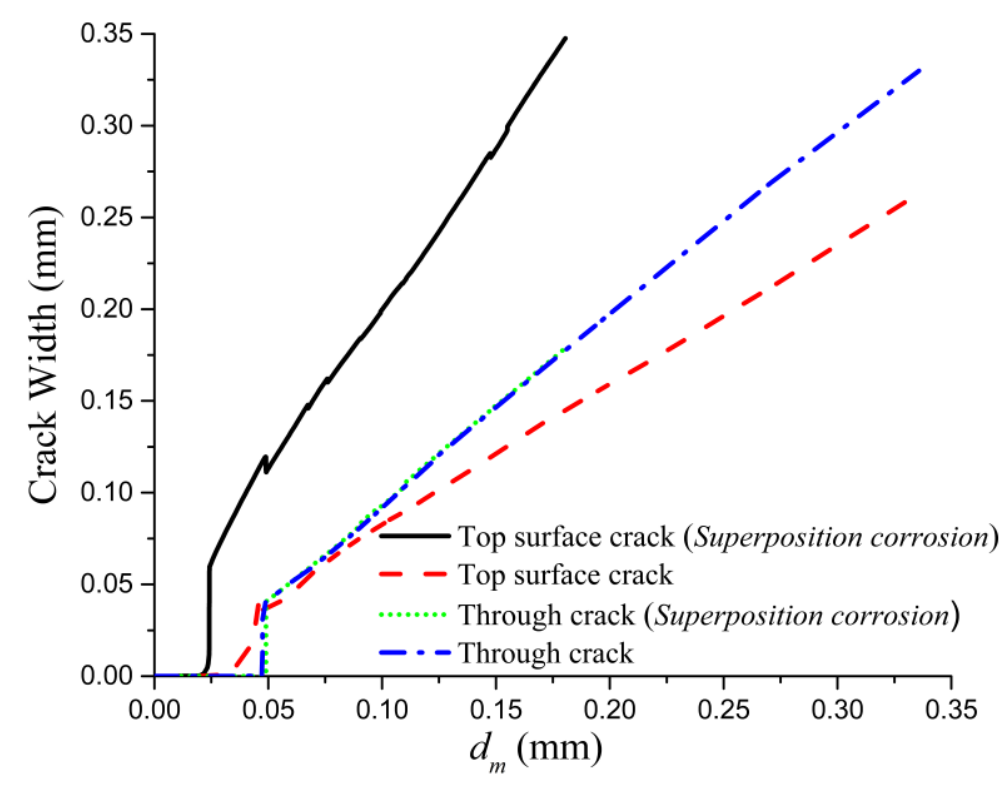

Figure 23 Crack width as a function of corrosion expansion displacement for cases of superposition and non-superposition of the corner bar 